\title{
Decision making in the electricity sector using performance indicators
}

\author{
Nuno Domingues ${ }^{1,2}$ (D) Rui Neves-Silva ${ }^{2} \cdot$ João Joanaz de Melo $^{2}$ \\ ${ }^{1}$ ISEL-ADESPA, Rua Conselheiro Emídio Navarro, 1, 1959-007 Lisbon, Portugal \\ 2 FCT-UNL, Campus Caparica, 2829-516 Caparica, Portugal
}

Received: 16 February 2016/Revised: 23 August 2016/Accepted: 19 September 2016/Published online: 1 October 2016

(c) Joint Center on Global Change and Earth System Science of the University of Maryland and Beijing Normal University and Springer-Verlag Berlin Heidelberg 2016

\begin{abstract}
The studies on the electricity sector are usually focused on the supply side, considering consumers as price-takers, i.e. assuming no demand elasticity. The present paper highlights the role of consumers on the electricity sector, assuming that consumers react to electricity prices and make decisions. Many studies focused on the demand side disaggregate consumers by activities, leading to a highly complex analyse. In the present paper, consumers are divided by three main types. In the present paper, the Government makes decisions on the measures to implement to influence the production and the consumption. To study the impact of the Government decisions, the present paper studies and implements a tool: a decision support system. This tool is based on a conceptual model and assists the task of test and analyse the electricity sector using scenarios to obtain a set of performance indicators that would allow to make quantitative balance and to eliminate unfeasible measures. The performance indicators quantify the technical, environmental, social and economical aspects of the electricity sector and help to understand the effect of consumer practices, production technology and Government measures on the electricity sector. Based on the scenarios produced, it is possible to conclude that the price signal is important for consumers and it is a way to guide their behaviour. It is also possible to conclude that is preferable to apply incentives on supporting energy-efficiency measures implementation than on reduce the price of electricity sold to consumers.
\end{abstract}

Nuno Domingues

nndomingues@gmail.com
Keywords Decision support systems - Demand elasticity · Energy efficiency and savings · Market-based instruments

\section{Introduction}

The European Single Act, adopted in 1986, emerges as the first revocation of the founding treaties of the European Communities in order to relaunch European integration and completing the internal market. By shifting the operating rules for the European institutions it defined the environment and common foreign policy (EU 2015). For two decades, the link between energy and the environment was more tenuous. The Treaty of Lisbon (initially known as the Reform Treaty) signed on 13 December 2007 by the European Member States puts the energy in the centre of European activity. The treaty was signed after the publication by the European Commission on 8 March 2006, the Green Paper: A European strategy for sustainable, competitive and secure energy. The European Member States can guide the behaviour of its agents to more sustainable consumption through various policy measures: fiscal measures, market instruments, price adjustments, incentives (in the form of penalties or benefits) and development of technologies energy (especially, the technologies dedicated to energy efficiency, renewable energy and lowcarbon technologies).

There is enough available information to understand the environmental and economic impact of energy consumption: what are their causes, their effects and some behaviorial changes (COM 2009; ECN 2012; EEA 2013; EuroStat 2014; GBE 2009; GEOTA 2013; IPCC 2006, 2014a, b). 
Despite the amount of information available, the implementation of measures without the need for capital investment is still residual: a conscious change energy consumption habits and investment in energy efficiency are not significant, which leads to poor use of the potential of energy saving in various sectors.

In several countries, the energy sector (especially electricity) has been undergoing changes in order to move from a vertically integrated system and set to a free and competitive market. In Portugal, the energy sector is still characterised by a competitive residual offer, behaving like an oligopoly of companies with high market power index and a search without power of decision, and the consumers assumed to be passive agents in the formula of the energy price calculation (EDP 2014; Endesa 2014; ERSE 2014; GALP 2014).

There are still flaws in the world that do not allow markets to function competitively and efficiently. These flaws are primarily related to property rights over natural resources and social externalities (EEA 2014).

The focus on environmental concerns resulted, for some time, in the legislation reforms and the use of market instruments (market-based instruments-MBI) with three objectives: to decarbonise the economy, promote energy efficiency in consumption and increase the share of energy renewable production (EEA 2012). However, with few exceptions (e.g. Sweden and Denmark), market instruments are not being efficient in Europe. The fact that there is still artificially cheap energy (whose selling price does not reflect its cost), wasting (low energy efficiency in various sectors) and weak regulation of the electricity sector (not being totally independent of the state) is indicated as the cause of lack of appropriate instruments or as the cause of the ineffectiveness of the chosen instruments (GBE 2009). But, another failure utterance factor of the adopted fiscal instruments is in its genesis: in most European countries, fiscal instruments are often designed under pressure (to increase tax revenue or for electoral reasons), attending only to the national context (introducing inequalities neighbouring countries) (OECD 2015a, b), without analysing the interaction with other external sectors the electricity sector (in order to account for externalities) (Abreu 2007; Cabral 2012) and with a tendency to belittle environmental protection (Bosquet 2000; OECD $2015 \mathrm{a}, \mathrm{b})$. We are witnessing thus to a reduction of ecotaxes, the ineffectiveness of emissions trading and many countries make short-term commitments in the energy and environmental regulation (Bosquet 2000).

Although there are examples of environmental protection measures, tailored to different countries that produce tax revenue (COM 2015; EEA 2014) and the role of taxes in the technological evolution (COM 2010), sustainable development has been assumed to economically expensive and an obstacle to a quick recovery of the economy.

Needs, then an assessment of the efficiency of policy measures available for the electrical sector and proves to be essential to have support systems decision (SSD) that quantify in order to evaluate its effects, to guide the electricity sector agents in their decision making. With this, you can check whether it is possible to switch to a new paradigm of reducing unemployment, economic recovery and increased quality of life, achieving environmental targets (EEA 2012). On the other hand, you can also check whether it is preferable to maintain the current paradigm for lack of better alternative policy measures to be implemented.

The assessment of policy measures to be implemented involves the complex task of analysing the combination of instruments and quantifies the expected fiscal, economic, environmental and social benefits. The impact of existing policies and proposed policies is essential to assess the effectiveness and efficiency of each instrument in achieving its stated objectives. Foreseeing these impacts is helpful to anticipate the acceptance of measures to identify potential sensitive groups, to quantify the gains and losses, possible to implement compensatory measures to plan the phasing of implementation and to fine tune the measures.

So the conditions for applying the SSD to complex matters involving several specialties, such as the problem of this paper are created. There is the opportunity to correct the shortcomings in the state of knowledge, including introducing consumer behaviour (reaction to prices and making decision to invest in energy efficiency and selfconsumption) and the state's role as regulator (be able to test measures political and quantify its effects in the electricity sector).

It is the author's opinion that it is essential that agents are informed of the impacts of their decisions. The supply of the SSD performance indicators is intended to quantify the decisions, allowing the user to define and compare strategies.

The theme of the present time, the complexity of relations, interdisciplinary knowledge, building a tool and a group of very diverse users are a strong set of reasons for the choice and development of this paper topic.

\section{The model}

\subsection{The DSS implemented can be generically represented by Fig. 1}

As inputs, the model has the control variables and the uncontrolled variables. The control variables can be seen as 
Fig. 1 General model

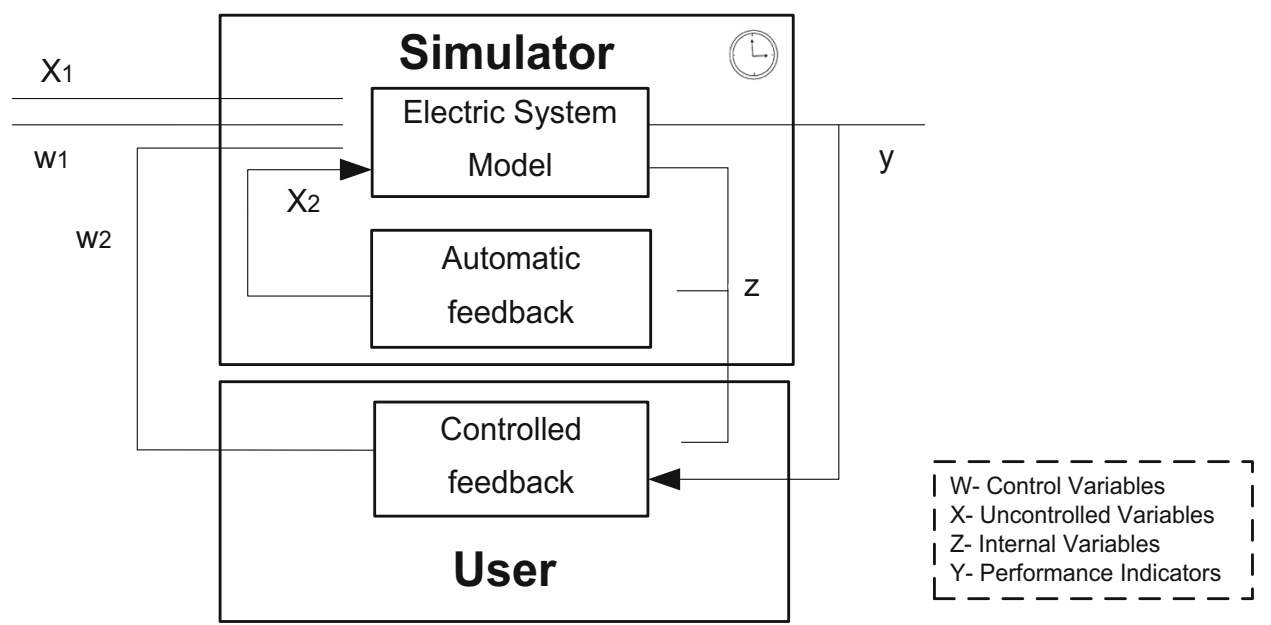

knobs and levers available for the user and can be introduced by the user $\left(\mathrm{W}_{1}\right)$ or validated by the user $\left(\mathrm{W}_{2}\right)$. The action «Validation» consists on correct or accept the forecast data: costs, prices, incentives, technical production data and consumer practices. The uncontrolled variables represent the variables that the user has no power over it and can be imposed data $\left(X_{1}\right)$ or data generated by the simulator $\left(\mathrm{X}_{2}\right)$.

The internal variables are the parameters (characteristics of the system, the physical constraints and the boundary conditions, for example) and mathematical results of the inputs that provide data for the feedback mechanism to forecast data.

The model has two outputs: a set of data for the feedback mechanism and a set of performance indicators. After each simulation period, the user can make decisions on the production side, on the consumption side or on the Government role.

Figure 2 illustrates the model diagram of the present paper.

The model starts to forecast the demand based on the consumer activities. The consumer activities are divided in consumer needs (based on the technology used and on the GDP) and in consumer practices (reaction to price and decision to invest in energy efficiency and self-production). The consumer practices influence the market behaviour by the demand quantity.

The system manager receives the demand and the supply and calculates the energy mix of electricity. The energy mix of electricity depends on the production technology, on the installed capacity of each production technology, on the production costs, the regulation and on the Government incentives.

The cost and the tariff structures provide economical data.

The variables implicated in the diagram are listed in Table 1 .
The main relations between model variables and their temporal dependencies are:

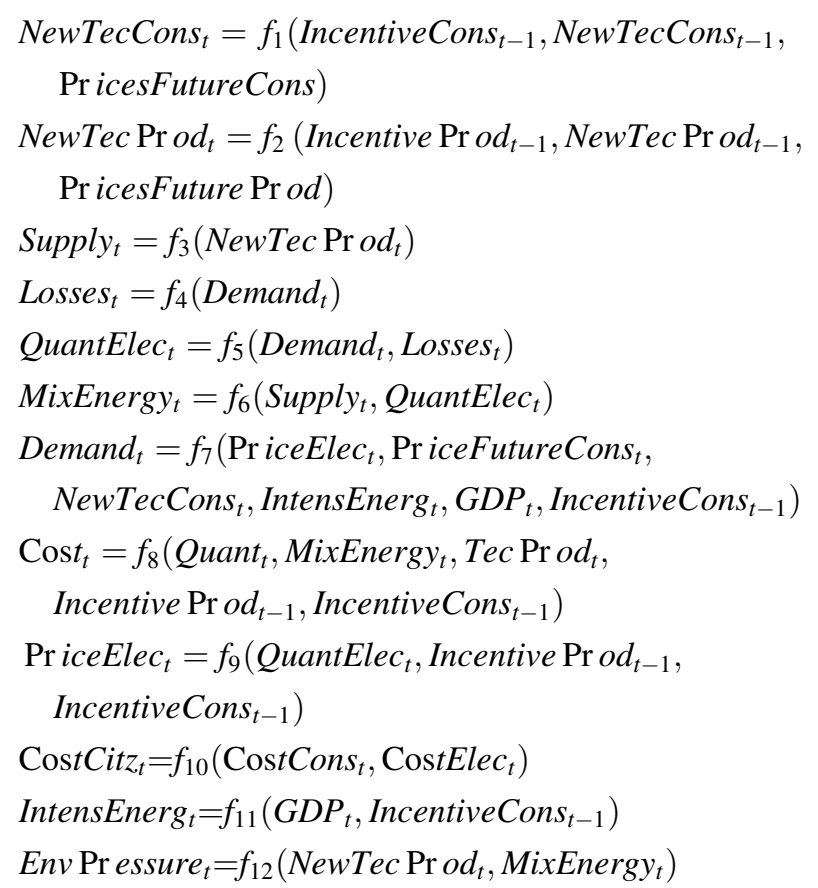

\section{Agents}

\subsection{Division and interaction}

It is assumed that the different agents and their interactions are resumed in Fig. 3.

The marketer as itself is not considered because depending on the action he is doing (buying or selling), he can be seen as a producer or a consumer for marketing proposes and is neutral for electricity production/consumption. The marketer has no investment costs and no 


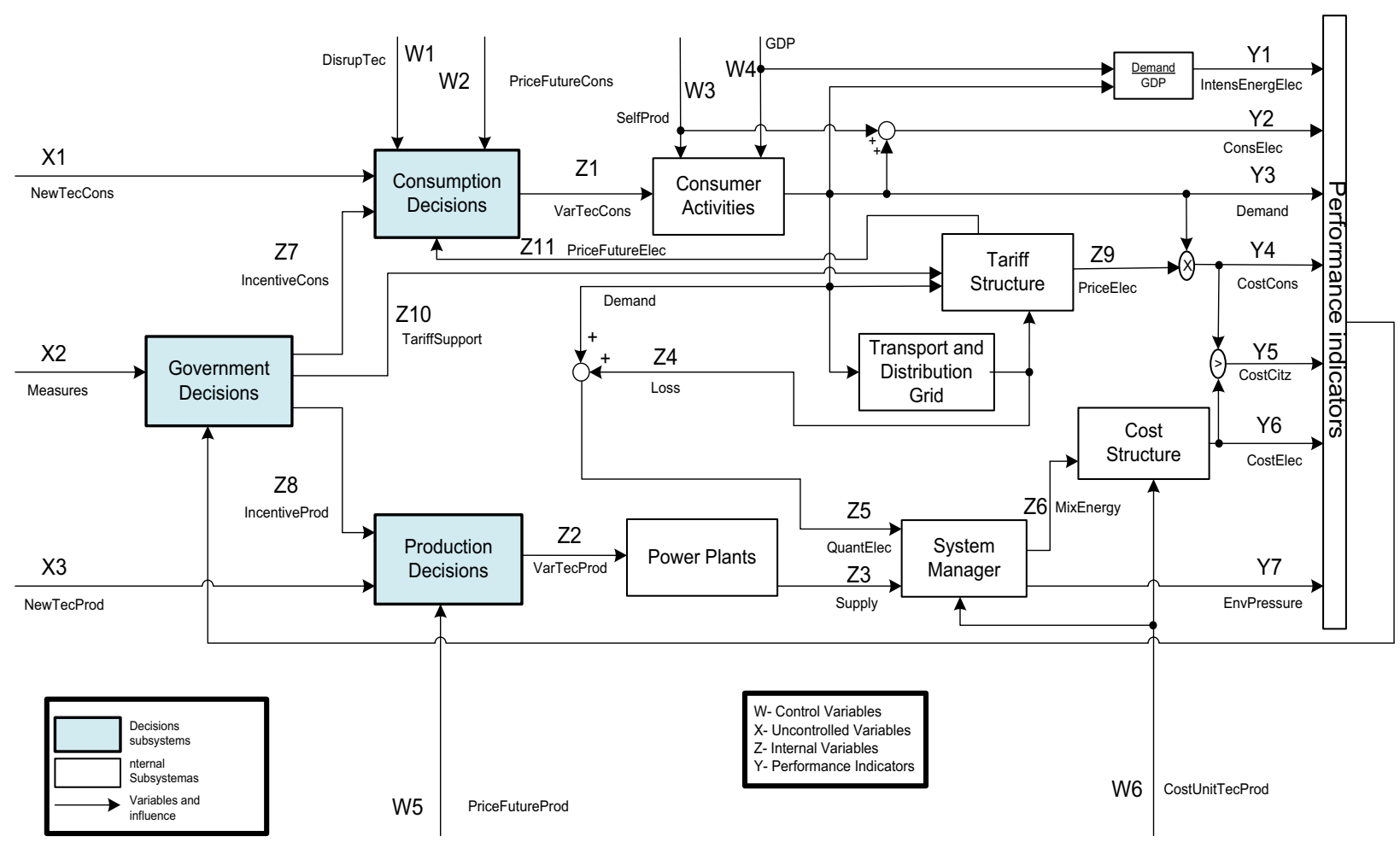

Fig. 2 Model diagram

sunk costs, but increases the market price by his transaction gain.

NGO and press are assumed as pressure groups that lobby and influence the electricity sector. However, they are not analysed separately because their influence is presented in the agents' behaviour.

\subsection{Consumers}

Consumers are represented by an elastic demand curve indicating the smashing effect of the electricity price.

The forecast of annual electricity demand is accomplished through causal interpolation. An accurate forecast requires precision in both in the economic, the consumer type and the energetic aspects of the electricity consumption, i.e. there are several factors that influence the natural evolution of electricity demand: demography, use of special equipment (e.g. air conditioning, heat pumps), electricity price, the price of the substituting energies, family income (or budget or their purchasing power) variation, GDP, Government spending, productivity, stock, wages, capital, fiscal balance, trade balance, unemployment, precipitation, high and/or low temperature, for example. In the present paper, it is assumed that demand depends mainly on GDP, price and price variation. The mathematical equations of the forecast are: $\begin{aligned} \text { Demand }_{t}= & \text { IntensEnerg }_{t-1} G D P_{t}-\delta \frac{\Delta \text { Pr iceElec }_{t}}{\text { Pr iceElec }_{t}} \\ & - \text { EficQuantCons }_{t}\end{aligned}$

where $t$-year, Demand-demand forecast, $G D P$-gross domestic product, IntensEnerg —electricity energy intensity of GDP, $\delta$-demand elasticity, PriceElec - electricity price, EficQuantCons-energy-efficiency measures implemented.

It is assumed that the energy intensity is changing every year according to the natural evolution of existing technology in the period, according to the reaction of consumption compared to the price (i.e. adjusting to the needs and comfort level) and in accordance with the energy-efficiency measures implemented in preceding periods. For the year, energy intensity is given by:

IntEnerg $_{t}=\frac{\text { Demand }_{t}}{G D P_{t}}$

All available data are illustrated in Tables 2 and 3. GDP and average price values are 2013 constant values.

Using causal interpolation, the demand forecast equation is:

Demand $_{t}=-59012.1+0.61 G D P_{t}-0.69 \frac{\Delta \text { PriceElec }_{t}}{\operatorname{Pr} \text { iceElec }_{t}}$

The electricity daily consumption is given by the load diagram. A load diagram indicates the pair of values (consumption, hours) for a type of consumer for a day of 
Table 1 List of variables implicated in the conceptual model diagram

\begin{tabular}{|c|c|c|}
\hline \multicolumn{2}{|c|}{ Variable } & \multirow{2}{*}{$\begin{array}{l}\text { Description } \\
\text { New technologies available to the consumer sector }\end{array}$} \\
\hline$X 1$ & NewTecCons & \\
\hline$X 2$ & Measures & Philosophy and political criteria \\
\hline$X 3$ & NewTecProd & New technologies available for the production sector \\
\hline$W 1$ & DisrupTec & Disruptive available technology \\
\hline$W 2$ & Self-Prod & Decentralised production of electricity \\
\hline$W 3$ & PricesFutureCons & Forecasted future prices to the consumer of the diverse forms of energy to replace electricity \\
\hline$W 4$ & GDP & Gross Domestic Product \\
\hline W5 & PricesFutureProd & Forecasting future prices to the producer of the diverse forms of primary energy to produce electricity \\
\hline W6 & CostUnitTecProd & Unit cost, by technology of power plant \\
\hline$Z 1$ & VarTecCons & Changes in technology in the consumer sector \\
\hline$Z 2$ & VarTecProd & Changes in technology in the production sector \\
\hline$Z 3$ & Supply & Electricity quantity available for production \\
\hline$Z 4$ & Losses & Grid self-production and losses of the electricity sector \\
\hline$Z 5$ & QuantElec & Electricity quantity \\
\hline Z6 & MixEnergy & Share of primary energy for electricity generation \\
\hline$Z 7$ & IncentiveCons & Government incentives for the consumption sector \\
\hline$Z 8$ & IncentiveProd & Government incentives for the production sector \\
\hline$Z 9$ & PriceElec & $\begin{array}{l}\text { Average price of electricity to consumers defined by the tariffs (in the regulated system) or by the market (in } \\
\text { liberalised regime) }\end{array}$ \\
\hline$Z 10$ & TariffSupport & Government incentives to the selling price of electricity \\
\hline$Z 11$ & PricesFutureElec & Future prices of electricity for the period under review \\
\hline$Y 1$ & IntensEnerg & Energy intensity of GDP \\
\hline$Y 2$ & ConsElec & Total electricity consumption \\
\hline$Y 3$ & Demand & Electricity demand \\
\hline$Y 4$ & CostCons & $\begin{array}{l}\text { Consumer electricity costs, according to the price of electricity to consumers defined by the tariffs (in the regulated } \\
\text { system) or market (in liberalised regime) }\end{array}$ \\
\hline Y5 & CostCitz & Cost of electricity to citizens \\
\hline$Y 6$ & CostElec & Total cost of production, transmission and distribution of electricity \\
\hline$Y 7$ & EnvPressure & Emissions, land use and other environmental impacts of production, transport and distribution of electricity \\
\hline
\end{tabular}

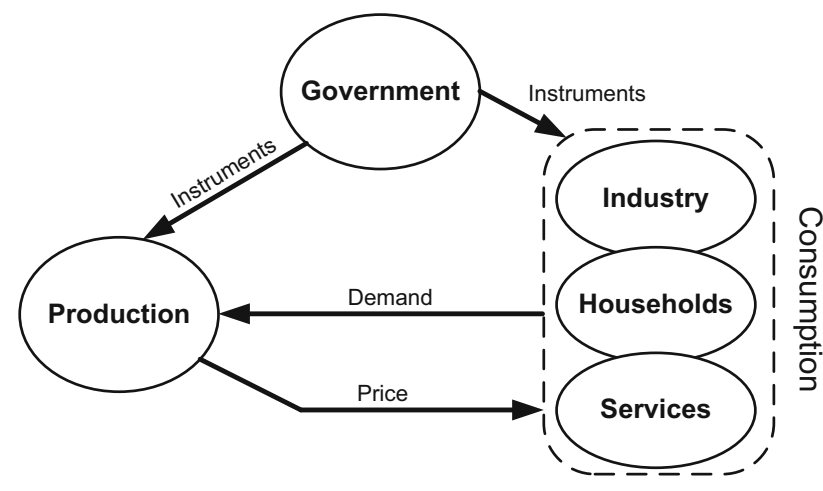

Fig. 3 Agents and their interaction

the week. To forecast the electricity daily consumption curve in Portugal, three major consumer types where analysed: households, industry and services. Each individual consumer has its own load diagram.
The present paper simplifies the load diagram by using the simple triangle rule. The single trapezium rule, which applied for different sections of the load diagram, can be illustrated as Fig. 6, taking in reflection the consumption profile defined by Fig. 4 .

And mathematically by the equation

$T(f)=\frac{(f(a)+f(b))(b-a)}{2}$,

matching exactly to the value of the area of the trapezoid defined by the interpolating line and reducing the infinite points of the load diagram to only seven points.

For a large number of households, the simplified load diagram is illustrated in Fig. 5.

The next step was to typify the seasonal load curves, assumed to be: summer, winter, summer holidays, winter holidays, higher energy consumption day, highest peak consumption day and lowest peak consumption day. In 
Table 2 Electricity consumption, GDP and average price 1995-2004 Source: (Pordata 2014; REN 2014)

\begin{tabular}{lrrrrrrrrrr}
\hline Year & \multicolumn{1}{c}{1995} & \multicolumn{1}{c}{1996} & \multicolumn{1}{c}{1997} & 1998 & 1999 & 2000 & 2001 & 2002 & 2003 & 2004 \\
\hline Demand (MWh) & 29,282 & 30,885 & 31,944 & 33,809 & 35,801 & 37,931 & 40,015 & 40,666 & 43,061 & 45,498 \\
GDP (M€ 2013) & 136,505 & 141,278 & 147,531 & 154,600 & 160,612 & 166,695 & 169,934 & 171,241 & 169,641 & 172,714 \\
Average price (€/MWh 2013) & 196 & 189 & 185 & 182 & 170 & 164 & 159 & 157 & 156 & 156 \\
\hline
\end{tabular}

Table 3 Electricity consumption, GDP and average price 2005 a 2013 Source: (Pordata 2014; REN 2014)

\begin{tabular}{|c|c|c|c|c|c|c|c|c|c|}
\hline Year & 2005 & 2006 & 2007 & 2008 & 2009 & 2010 & 2011 & 2012 & 2013 \\
\hline Demand (MWh) & 47,940 & 49,176 & 50,058 & 50,596 & 49,884 & 52,198 & 50,510 & 49,060 & 50,188 \\
\hline GDP $(M € 2013)$ & 174,038 & 176,741 & 181,146 & 181,507 & 176,101 & 179,445 & 176,167 & 170,326 & 168,018 \\
\hline Average price (€/MWh 2013) & 156 & 154 & 157 & 158 & 166 & 169 & 169 & 172 & 176 \\
\hline
\end{tabular}

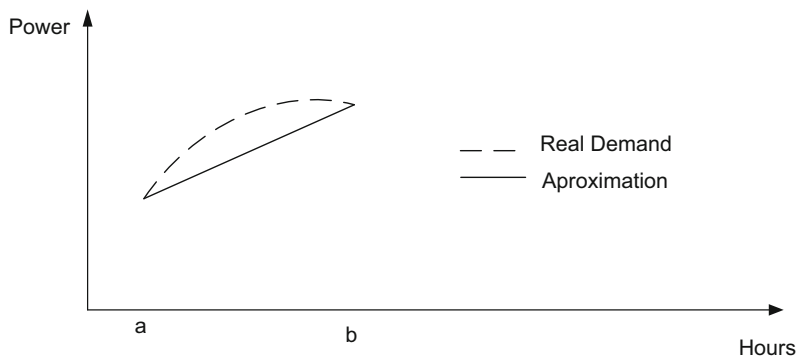

Fig. 4 Trapezium rule (single)

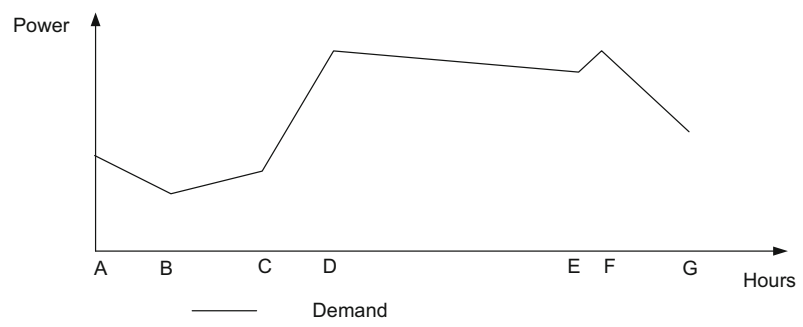

Fig. 5 Typical load diagram. A Consumption at $00 \mathrm{~h} 00 \mathrm{~min}$, $B$ minimum super off peak, $C$ home consumption growth in the mornings (households consumption followed by the start of business activity), $D$ peak daytime, $E$ end of work and business activity, $F$ night peak, $G$ consumption at 24 h $00 \mathrm{~min}$

addition, the first four groups were divided into weekdays and weekend. Thereby, these 13 days were used to represent all the 365 days of a year.

Other than households, the electric system has companies (services and industry) as consumers. Similar study was made for these types of consumers, considering the load diagram profile of them.

\subsection{Producers}

Another agent is the producer representing the plant owner and the investor in new power plants. The plant owner is

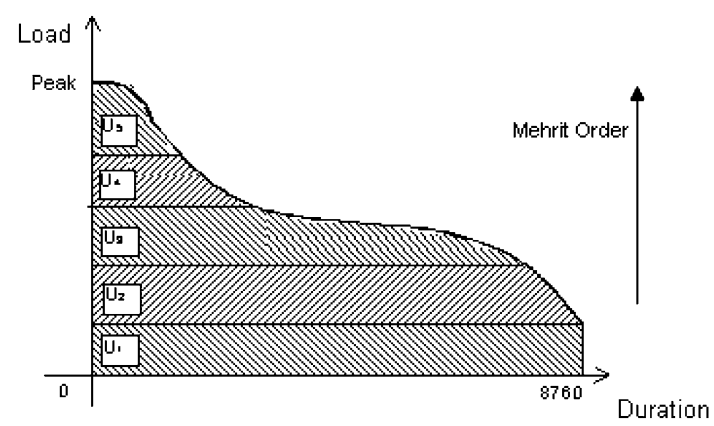

Fig. 6 Load duration diagram by loading criterion Source (Dorf 1997)

influenced by historic data and the regulated prices. The plant owner influences the price by the quantity willing to sell. The investor in new power plants producer is sensitive to the initial investment and the payback time and usually looks for the opportunity cost to balance investments. Both the plant owner and the investor in new power plants are influenced by the available technologies, the load flow, the regulation and the available incentives.

The production is characterised by no storage (need for production, grid and consumption coordination) homogeneous product (impossible to differentiate it).

The energy mix is obtained by the load duration diagram, the same used to planning, accordingly to the load consumption forecast.

The load duration diagram is determined by the loading criteria. This diagram is represented by several generating units, whose position is subject to a merit order. Figure 6 illustrates an example for 5 units.

The system management takes into account the total costs, not only the marginal. Thereby, the merit order is based on the average cost at full load. Each area in the Figure represents the total energy produced by the unit $\mathrm{U}_{\mathrm{i}}$ 
in a year. For a determined number of hours worked annually, $\mathrm{h}$, the unit annual energy generated the power $\mathrm{P}$. If it worked $8760 \mathrm{~h} /$ year, then one can calculate the relative power to h by:

$$
P_{\text {Rel }}=\frac{P . h}{8760}
$$

\subsection{Government}

The Government is also a consumer. However, in the present paper, it is highlighted three other important roles:

- to define a national regulatory framework in the European context

- to design the national budget (along with the parliament) to define the incentives (benefits and/or penalties), the market-based instruments (MBI)

- to «validate» the tariff structure (designed by ERSE).

The first role is based on command-and-control approaches (regulations, prohibitions, standards, requirements or recommendations), where the Government sets a target and orders the agents to control their activities to meet that target. Command-and-control approaches mainly impose technology-based standards or performance-based standards.

Technology-based standards designate the technology to be used. Performance-based standards involve a precise boundary (establishing impact limits for each source), so the variables to control must be measurable. Otherwise, technology-based standards are more appropriate. Performance-based standards are more versatile, since they do not specify the technology, making them more cost-effective and easily adapted to results of $R \& D$ and conjuncture.

The second role defines measures to influence the agent's decisions. The incentive mechanism affects the costs and prices, which will influence production and consumption behaviour. Economic MBI, by contrast, include the price signal of the instrument in the agent direct costs. MBI is not always the most effective approach to protect the environment or for Governments to raise revenue. However, its value is be close to both objectives at the same time and examining benefits trade-offs, thereby seen as complementary to regulatory approaches, as a fundamental part of a policy mix rather than stand alone measures. Complementary measures can be investments in infrastructure (electrical grid or communications), research and development (R\&D) funding, job creation, education (social or company), etc.

Electricity regulator should be an independent entity from the Government. However, it is a fundamental aspect of a Country. Thereby, Electricity regulator and Government should cooperate. The Government «validation» of the tariff structure could be to avoid prices to high that put away from the basic needs (cooking, heating, cleaning, for instance) citizens with poverty and for economy boost (as a way to finance industry or companies that deliver public goods, for example). It consists on comments and suggestions on the draft version of the tariff structure designed by the independent national regulator.

In the focus of the present paper, regulation must contribute to define an accurate market model and define the future electricity business model: define the overall target and let the market decide who will invest in what: new technologies and primary energies to be introduced or phased out.

Policy makers, decision makers and stakeholders (business or political) react appropriately to different events occurring in their areas of activity such as:

- fixed changes and new requirements of the market in which they operate

- impact of technological advances

- new processes in organizational management

- new models of data storage and management

- changes in attitude, tactics and strategies in business.

The relevant available measures for the energy sector are illustrated in Table 4.

While some fiscal instruments can be used to directly tackle environmental problems, subsidies or tax exemptions can inadvertently cause environmentally damaging behaviour. These are called harmful subsidies. For example, a social tariff for households and subsidised prices to industry compete with energy-efficiency and savings measures. Most of these types of subsidies are paid directly from the budget; thereby, fiscal costs are easy to report.

There are two main approaches in introducing policy measures:

reforming the tax system by a focus only on the energy consumption and environment impact;

shifting the tax burden from employment, family budget and capital (economic goods) to pollution, resource depletion and waste (environmental bads), mainly known as environmental fiscal reform (EFR). EFR can contribute to help to achieve the Millennium Development Goals of «halving absolute poverty by the year 2015» and «reversing the loss of environmental resources».

The introducing of incentives influences the consumer decisions by changing the reflected price.

The market price, $P_{E}$, and quantity, $Q_{E}$, are set by the market equilibrium (point $E$ ), obtained by the intersection of the demand and the supply curves, as illustrated in Fig. 7.

The area $P_{D} E P_{E}$ represents the consumer's welfare because consumers were willing to pay more, but they are 
Table 4 Available policy measures

\begin{tabular}{|c|c|c|c|}
\hline & \multicolumn{2}{|l|}{ Direct } & \multirow[t]{2}{*}{ Indirect } \\
\hline & Price & Quantity & \\
\hline \multicolumn{4}{|l|}{ Regulatory } \\
\hline \multirow[t]{4}{*}{ Capital } & $\begin{array}{l}\text { Direct transfer fund or grant (e.g. gas pipeline } \\
\text { subsidising) }\end{array}$ & Pool (tendering system) & National energetic plan \\
\hline & \multirow[t]{3}{*}{ Fiscal incentives (tax credits) } & $\begin{array}{l}\text { Direct transfer fund or grant (e.g. electric } \\
\text { vehicle) }\end{array}$ & Accelerated depreciation \\
\hline & & & Benefited interest rate \\
\hline & & & EU directives \\
\hline \multirow[t]{3}{*}{ Production } & Feed-in tariffs (FIT), PRE producers & Environmental fiscals & \multirow[t]{3}{*}{ Market access restrictions } \\
\hline & \multirow[t]{2}{*}{ Environmental bonus } & Green certificates (TGC) & \\
\hline & & $\begin{array}{l}\text { Municipality tax paid by wind power } \\
\text { plants owners }\end{array}$ & \\
\hline \multirow[t]{2}{*}{ Consumption } & Demand quotas & Consumer tariffs (defined by ERSE) & Sales tax \\
\hline & $\begin{array}{l}\text { Subsidising consumption (electricity and gas } \\
\text { deficit) }\end{array}$ & Green Procurement & Tax credits, exemptions or rebates \\
\hline \multicolumn{4}{|l|}{ Voluntary } \\
\hline \multirow[t]{2}{*}{ Capital } & Shareholder programs & & R\&D (e.g. PV in Amareleja) \\
\hline & Contribution programs & & $\begin{array}{l}\text { Funding for first-of-a-kind and } \\
\text { early scale }\end{array}$ \\
\hline Production & Green tariffs & $\begin{array}{l}\text { Bilateral agreements on demand } \\
\text { guarantee }\end{array}$ & $\begin{array}{l}\text { Connectivity between } \\
\text { international markets }\end{array}$ \\
\hline Consumption & Passenger emissions flight compensation & $\begin{array}{l}\text { Bilateral agreements on security of } \\
\text { supply }\end{array}$ & \\
\hline
\end{tabular}

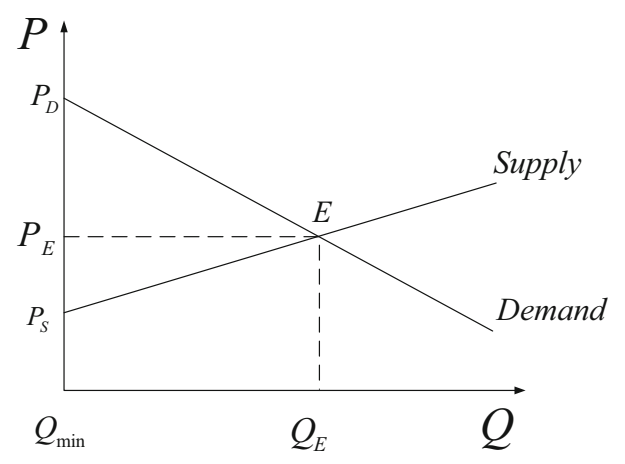

Fig. 7 Market behaviour

paying less. The area $P_{E} E P_{S}$ represents the producer's surplus because consumers were willing to receive less, but they are receiving more.

Consumers demand $(Q)$ will take account the price of electricity $(P)$ and the family budget $(I)$ plus benefits $(B)$ and minus the penalties $(A)$.

The simplest way to understand how incentives (benefits and penalties) influence the market behaviour is by partial equilibrium analysis. This type of analysis considers only the directly impact on the equilibrium price (and thereafter, the market price and quantity), by the proposed incentive (and thereafter, the costs and the supply curve).

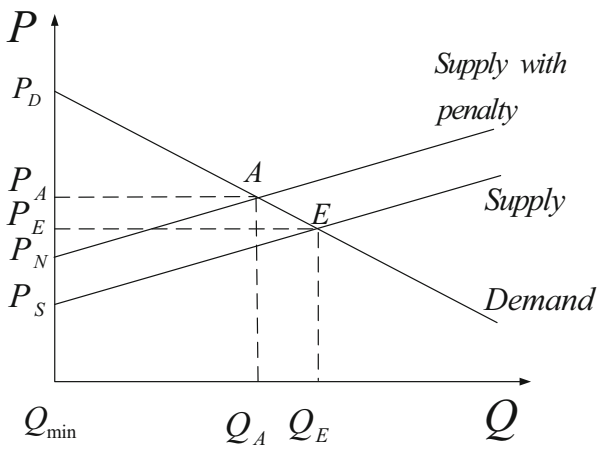

Fig. 8 Impact of price and penalty on market

Considering environmental impact, the lack of a damage penalty has the same effect as the introduction of a benefit and the removal of a harmful benefit has the same effect as the introduction of a penalty.

At market closure, the market equilibrium will be at a higher price and lower quantity. Figure 8 illustrates the impact of price and penalty on market.

The difference $P_{A}-P_{E}$ is related to the impact externalities (or the expense that was supported by the Government, in the case of an incentive removed) that were not being paid. The difference $Q_{A}-Q_{E}$ is related to 
the fewer consumers willing to pay the higher prices (or the right prices).

The consumer's welfare reduced by the area $P_{A} A E P_{E}$, i.e. the difference between the area $P_{D} E P_{E}$ and the area $P_{D} A P_{A}$. This fact seems negative but, in fact, it's positive. One should know that the difference $P_{A}-P_{E}$ related to the impact externality is paid by all or increases the national debt. When price adjustment is made, there is transparency (consumers know the cost of the consumption), the pollution is paid by polluters and the extra money can be used to mitigate the impacts, invest in overall efficiency or reduce the debt.

The producer's surplus reduced (as it was expected) from the area $P_{S} E P_{E}$ to the area $P_{N} A P_{A}$. This can influence the producers to invest in better processes, energy and products to avoid or reduce the penalty factor and, thereby, increase their surplus. As in the consumer's analyses, the remaining budget will be for the Government.

The introduction of a benefit will lower the supply curve. At market closure, the market equilibrium will be at a lower price and higher quantity. The difference $P_{E}-P_{B}$ is related to the subsidy. The difference $Q_{A}-Q_{E}$ is related to the more consumers willing to pay the lower prices (or the subsidised prices).

Figure 9 illustrates the impact of price and benefit on market.

The consumer's welfare increased by the area $P_{E} E B P_{B}$, i.e. from the area $P_{D} E P_{E}$ to the area $P_{D} B P_{B}$. This fact seems positive but, in fact, it's negative because the price adjustment is paid by all and not by consumers in tax, national debt and/or degradation in overall efficiency.

The producer's surplus increases (as it was expected) from the area $P_{E} E P_{S}$ to the area $P_{B} B P_{M}$. This can influence the producers to postpone capitals in better processes, energy and products to avoid or reduce the penalty factor and, thereby, increase their surplus. As in the consumer's analyses, the remaining budget will be supported by the Government.

In order for agents to make conscious decisions, the markets must give good information, including the full cost of the products. Subsidies therefore tend to take the form of price controls, where the provision of a good or service is priced at a level below the full cost of supplying it.

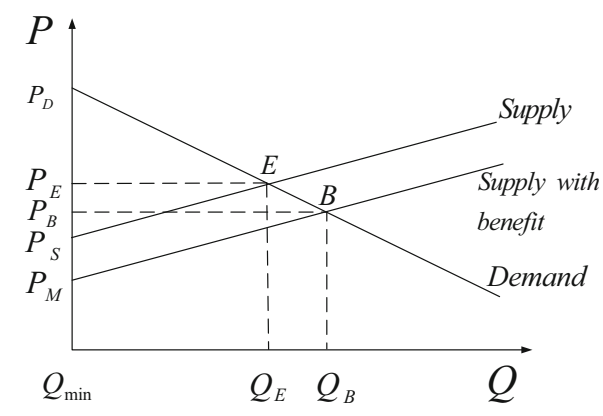

Fig. 9 Impact of price and benefit on market
For industry and services, in general, reforms increase the costs of production. When these costs cannot be completely transmitted to suppliers, consumers, Government or third parties, there are potential losses of competitiveness. However, these short-term costs may encourage investments on more energy savings, environmentally and economically efficient production and innovation in the longer-term. Larger companies are keener to do it (because even small per unit better performance will return in great global cost decreases), but other companies could have less affordability.

\section{Models}

\subsection{The technological models}

These models feature a bottom-up approach to engineering, containing a detailed description of the technology and technical potential. Production technologies are described in detail and using disaggregated data, allowing you to identify a set of technical options (existing and emerging). There are several approaches to the analysis of energy consumption.

The forecast energy demand is independent of the behaviour and market restrictions. These models assume that agents evaluate the technology options and costs directly responsive to investment incentives and subsidies prices. They are good to identify cost-effective investment opportunities (no regrets actions).

The identified disadvantages in the interaction between the energy sector and other economic sectors are: First, the economic effects of technological choice are not analysed (Jaccard et al. 2004); second, they are not considered the production scale dimensions (Rutherford and Böhringer 2006); third, are not considered the subjective choices of the consumer only that the technologies are perfectly substitutable on the basis of costs and emission levels (Hourcade et al. 2006) and fourth, the risk of transition to a new technology has a higher risk because the period return will increase the different technologies in consumption is small and consumers are generally less informed (Sutherland 1991). So, in addition to underestimate the costs, these models overestimate the willingness of consumers to replace technologies, there is a risk of potential for improving efficiency be overestimated (Capros 1995; Rivers and Jaccard 2005).

\subsection{The general equilibrium models}

These models feature a top-down approach with a global vision and highly aggregate of the economy, including different sectors, markets and their interactions. Not 
explicitly represent the technologies available in the market, usually being a rudimentary treatment (Rutherford and Böhringer 2006). They assume that technological change is trend-based rates (usually exogenous) and do not disaggregate the available technologies for efficiency levels. So, do not identify cost-effective investment opportunities (no regrets actions) and underestimate the potential for improving the efficiency of the activities of consumption.

The model input data (such as the energy demand and the shares of each consumer type) are based on market behaviour and through aggregated economic indicators (such as GDP and yield) and behaviorial reactions (such as for example elasticities to price and conjectural variables) (Rivers and Jaccard 2006). It assumes historical trends seamless, despising disruptive variables. The energy sector is simplified: includes a constant elasticity of substitution, representing the preferences of consumers and the mathematical functions of production. The technical substitution possibilities are identified only by this elasticity (Capros 1995; Rutherford and Böhringer 2006). There are several approaches to the analysis of energy consumption. The models of neoclassical general equilibrium were only used for analysis of policy measures of the legal type, since formulate a market equilibrium oriented price. The models allow Keynesians general balance-imbalance conditions and function as a descriptive tool short and medium-term projections (Capros 1995; Löschel 2002; Rutherford and Böhringer 2006). The most common is the use of general equilibrium models that combine behaviorial assumptions (such as the rationality of economic agents) with the analysis of equilibrium conditions (Silva et al. 2010).

\subsection{Hybrid models}

Due to its own characteristics, each of the modelling approaches have strengths and specific limitations. Because the top-down models represent technological change in the abstract, this approach only helps policy makers to evaluate the policy instruments across the economy, being ineffective to evaluate the role of technology (Hourcade et al. 2006). Moreover, the elasticities of substitution between energy and energy-efficiency parameters are usually set through historical data, with no guarantee that they remain valid in the future, ignoring development of new technologies (Grubb et al. 2002). For this reason, the top-down models conclude that the improvement efforts and removal of a trend scenario are expensive (Hourcade et al. 2006; Jaccard et al. 2003; Rivers and Jaccard 2006). On the contrary, due to their technological detail, the bottom-up models allow you to set policies oriented technology. However, the bottom-up models indicate that the shift to a sustainable energy system can be achieved at a lower cost than real because it does not reflect the microeconomic behaviour of agents and macroeconomic interaction (Metz, 2001).

Thus, the use of separate bottom-up models and topdown does not adequately address all the issues. In this context, some studies support the need for an integrated hybrid structure combining their forces, building an instrument that is explicitly technological, behaviourally realistic and global economic, linking supply and power consumption to the changing structure of the economy and total production (Hourcade et al. 2006). The need to develop a hybrid model had recently been identified by national authors. After verifying that the use of bottomup and top-down TIMES_PT GEM-E3_PT model separately revealed that they determine different options. However, HYBTEP platform built by connecting the TIMES_PT and GEM-E3_PT models was used for climate-change mitigation options without consumer investment alternatives, but only by combining technological choices sectorally disaggregated macroeconomic responses (Silva 2014). The impossibility of modelling, with TIMES_PT, the long-term evolution of energy systems with high penetrations of renewable energy sources, was developed from the MiniCAM model, a new method with time resolution to develop investment plans (Pina 2012). The need to combine the top-down approach with the bottom-up to test empirical behaviour was developed hybrid model CIMS, simulating the carbon tax disincentives to gasoline vehicles and disincentives to vehicles only driver to show how different instruments policy can motivate technological change (Horne et al. 2005) or can define the policy measures necessary to achieve a minimum market share for lowemission vehicles (Jaccard et al. 2004).

\subsection{Existing models}

The simplicity and flexibility of the models allowed the appearance of several SSD, with a variety of available tools. There are certainly more SSD, but these are best known for their use, reliability and availability. The best SSD is essentially defined by the problem modelling.

A simulation tool is typically used for short-term analysis. A scenario-building tool is typically used for medium and long-term analysis. A balanced search tool is assumed that agents are price-taker and that there is an optimum balance. A top-down tool is macroeconomic. A bottom-up tool identifies and analyses specific technologies. An operation optimisation tool indicates the best operating point of a given power system. An investment optimisation tool indicates the best investment option in a power system.

The uncertainty of the results obtained by the models comes from the uncertainty of future conditions and the intrinsic characteristics of the model. 
Table 5 shows some existing models for the energetic sector.

\section{Decision support system}

The present DSS simulates an electric system regarding the technical, environmental and economical aspects. All agents need clear and consistent information concerning the real impact of policies in the economy, on the environment and to society. Agents also need a minimum of predictability, a stable framework, a reliable price signal, to trigger those decisions to invest in expensive, long-lived assets and avoid creating losers unnecessarily.

Bottom-up models are suited to investigate the impacts of climate or energy policy on the technologies portfolio (demand and supply side); to identify the low-cost abatement opportunities and design cost-effective technology-

Table 5 Existing models for the energetic sector. Source: Barros (2014), Blarke (2015), Boucinha (1991), Branquinho (2014), Carmona (2006), Connolly et al. (2010), Fortes (2014), Hourcade et al. (2006), Jaccard et al. (2004), Jaccard et al. (2003)

\begin{tabular}{|c|c|c|c|c|c|c|c|}
\hline \multirow[t]{3}{*}{ Model } & \multicolumn{7}{|l|}{ Type of tool } \\
\hline & \multirow[t]{2}{*}{ Simulation } & \multirow[t]{2}{*}{ Scenario } & \multirow[t]{2}{*}{ Equilibrium } & \multirow[t]{2}{*}{ Top-down } & \multirow[t]{2}{*}{ Bottom-up } & \multicolumn{2}{|c|}{ Optimisation } \\
\hline & & & & & & Operation & Investment \\
\hline AEOLIUS & Yes & - & - & - & Yes & - & - \\
\hline COMPOSE & - & - & - & - & Yes & Yes & Yes \\
\hline E4cast & - & Yes & Yes & - & Yes & - & Yes \\
\hline EMCAS & Yes & Yes & - & - & Yes & - & Yes \\
\hline EMINENT & - & Yes & - & - & Yes & - & - \\
\hline EMPS & - & - & - & - & Yes & Yes & - \\
\hline EnergyPLAN & Yes & - & Yes & - & Yes & Yes & - \\
\hline EPLAN & Yes & Yes & - & Partial & Yes & Yes & Yes \\
\hline EnergyPRO & Yes & Yes & - & - & - & Yes & Yes \\
\hline ENPEP-Balance & - & Yes & Yes & Yes & - & - & - \\
\hline GAMS & Yes & - & Yes & Yes & - & Yes & - \\
\hline GTMax & Yes & - & - & - & - & Yes & - \\
\hline H2RES & Yes & Yes & - & - & Yes & Yes & - \\
\hline HOMER & Yes & - & - & - & Yes & Yes & Yes \\
\hline HYDROGEMS & - & Yes & - & - & - & - & - \\
\hline IKARUS & - & Yes & - & - & Yes & - & Yes \\
\hline INFORSE & - & Yes & - & - & - & - & - \\
\hline Invert & Yes & Yes & - & - & Yes & - & Yes \\
\hline LEAP & Yes & Yes & - & - & Yes & - & - \\
\hline MARKAL/Times & - & Yes & Yes & Partial & Yes & - & Yes \\
\hline Mesap PiaNet & - & Yes & - & - & Yes & - & - \\
\hline MiniCAM & Yes & Yes & Partial & Yes & Yes & - & - \\
\hline NEMS & - & Yes & Yes & - & - & - & - \\
\hline ORCED & Yes & Yes & Yes & - & Yes & Yes & Yes \\
\hline PERSEUS & - & Yes & Yes & - & Yes & - & Yes \\
\hline PRIMES & - & - & Yes & - & - & - & - \\
\hline ProdRisk & Yes & - & - & - & Yes & Yes & Yes \\
\hline RAMSES & Yes & - & - & - & Yes & Yes & - \\
\hline RETScreen & - & Yes & - & - & Yes & - & Yes \\
\hline STREAM & Yes & - & - & - & - & - & - \\
\hline TRSYS16 & Yes & Yes & - & - & Yes & Yes & Yes \\
\hline UniSyD3.0 & - & Yes & Yes & - & Yes & - & - \\
\hline WASP & Yes & - & - & - & - & - & Yes \\
\hline WILMAR & Yes & - & - & - & - & Yes & - \\
\hline
\end{tabular}


based subsidies, emission or energy standards to increase the overall efficiency of the system. Their main weakness is to neglect the macroeconomic impact of different energy systems; thereby, it was necessary to introduce in the model the top-down problem for the GDP influence.

The simulator is built based on two tabs for the input data and five tabs for the output data.

The input tabs are divided in production and consumption areas, and they have predefined values that can be changed by the user, partially or totally. The items in those two input tabs are technical, environmental and economical associated. The production input tab is represented in Fig. 10

It is divided in economical and technical items, per technology. It is considered five technologies: wind, solar, hydro, coal and gas. There is also a possibility to add other technology with the aim to exercise the impact of a new technology or an existing one with different characteristics.

For the economical items, there are the variable (the unit fuel cost, de $\mathrm{CO} 2 \mathrm{e}$ emissions per unit produced, the associated $\mathrm{CO} 2$ tax and the variable O\&M), the constant costs (constant O\&M and constant costs per year), the incentives (the benefits and the penalties, variable per unit produced and constant per year) and also other constant costs per year as global. There are also other costs, where the user can introduce the system management costs and the ancillary services costs, for instance.
For the technical items, there is the capability factor for the renewable energy and the installed capacity for all technologies.

The consumption input tab is represented in Fig. 11.

It is divided in the share of consumption and the number of consumers for three different sectors: households, industry and services. For the same different sectors, there is also the variable term (by energy consumed) and the constant term (per month) of the tariff; and for the system, there is the VAT. There are also the items that influence the consumption: the efficiency measure to study (divided in the savings percentage, the sector(s) affected and the necessary investment) and the GDP. The date field is related to the data introduced in both input tabs. Finally, there is the path of the output file that will be filled automatically with the relevant data package generated by the simulation. If there is a "l" character in the path, one should double it. For example: if you pretend to save in the path c:MMyDatalOutput.csv, you should write c:IMMyDatallOutput.csv. The items «additional consumption » allows accounting for losses in the network, the self-consumption and other consumption. It can be in percentage or in units of energy or both. The other consumption may serve, for example, to reserve power for export to an abnormal condition (such as a sporting or cultural event that has significant impact on the electric field) for a counterpart (e.g. ensure minimum of water in reservoirs for agriculture

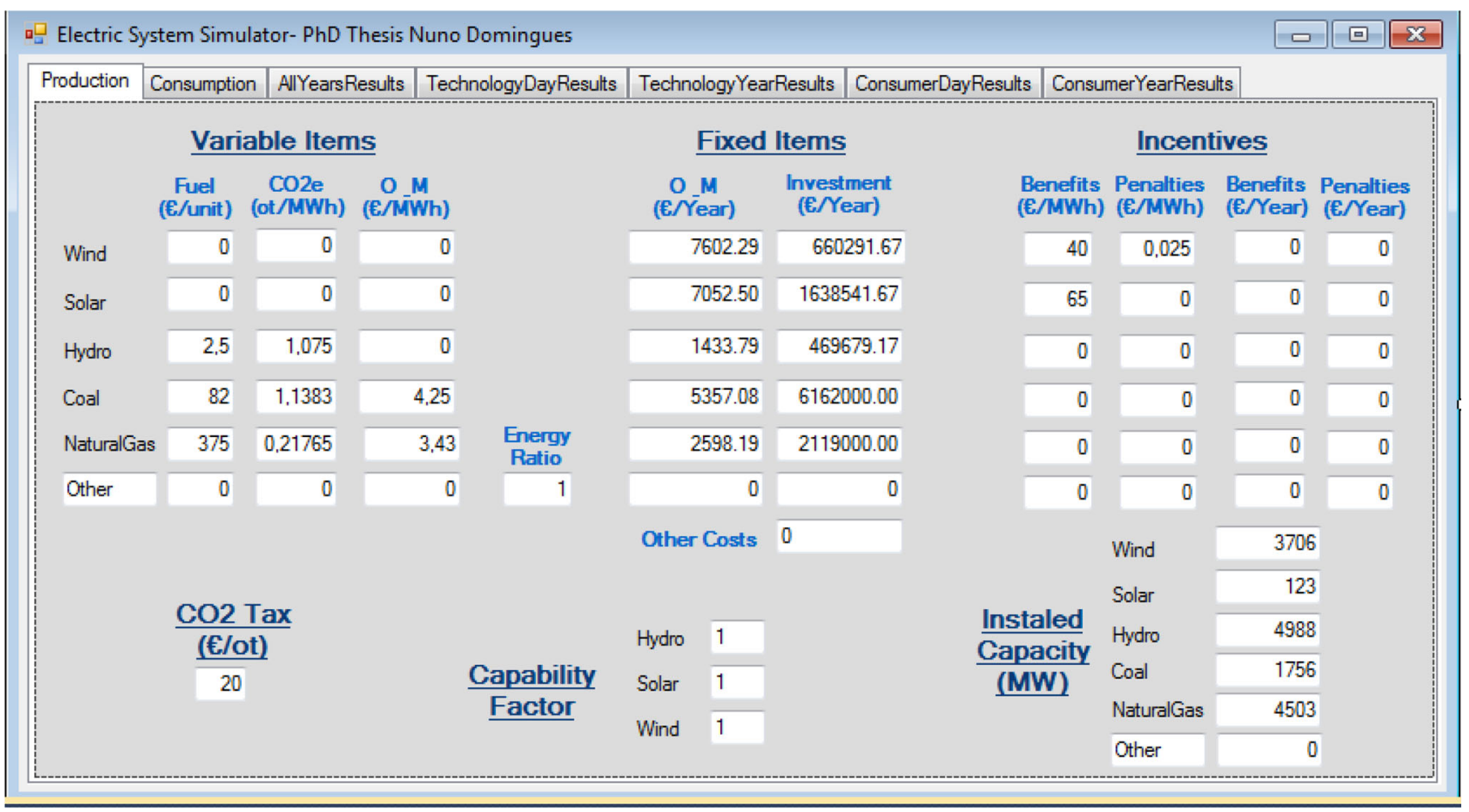

Fig. 10 Production input tab 


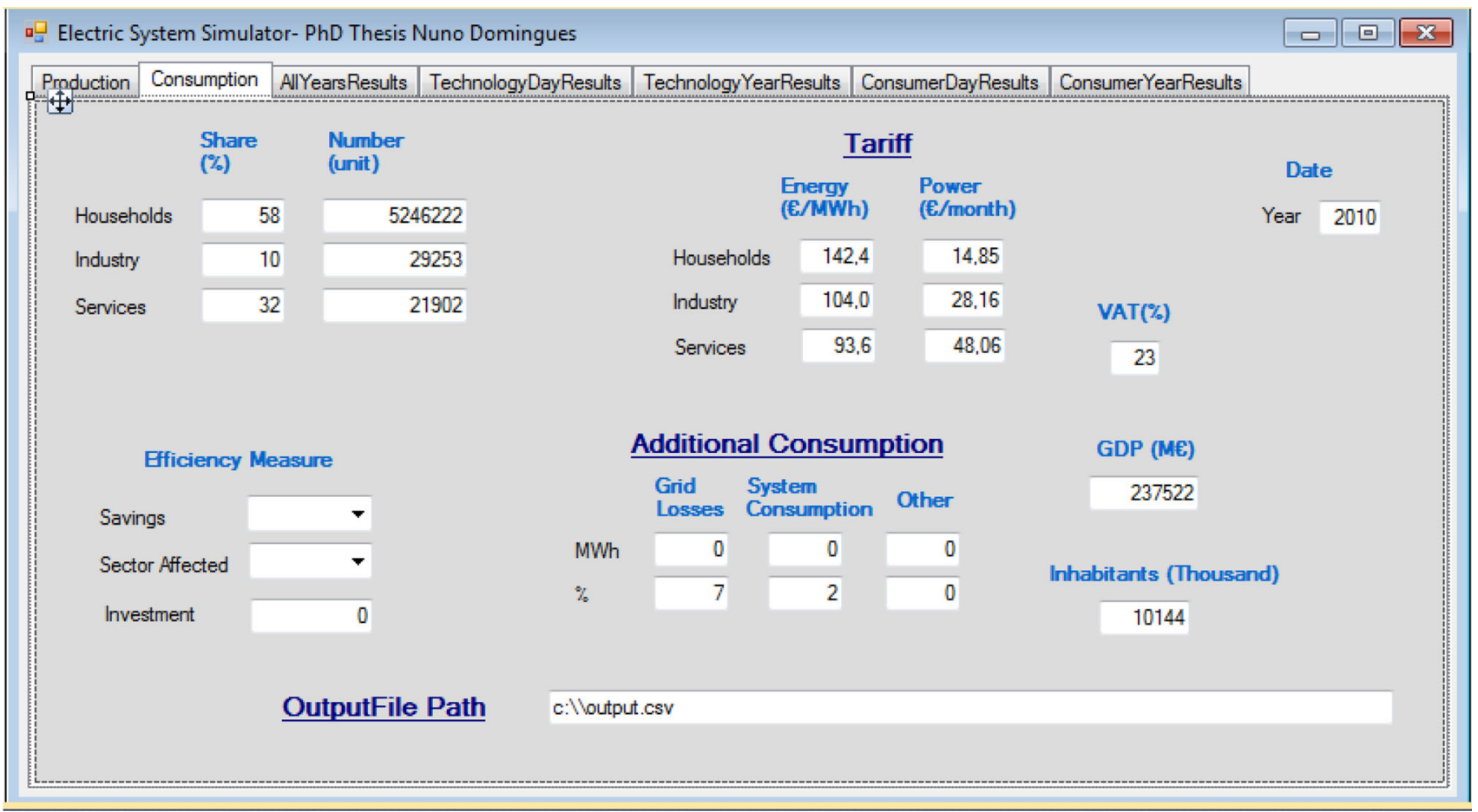

Fig. 11 Consumption input tab

or tourism, requiring extra boost) or other situation (as an item energy intensive during that year).

The output tabs are divided in total years overview and the production and consumption, by year and by day.

To start the simulation, one should click the run simulator button to simulate the year-by-year study. The forecast and the graphic zoom buttons are inactive in the simulation for the first year.

When the user wants to start the simulation for the next year, there are two options: use the forecast button to allow the simulator to generate data for the next year and then correct or accept the produced data or simple update the data in the input tabs. After that, the user should hit the run simulator button to produce the results for the next year.

At the end of simulation, the «AllYearsResults» tab shows two graphics for the 15 -year period simulated. The first graphic shows the energy consumption and the energy mix for the period in study. The second graphic shows a zoom of a technology selected.

This tab gives a general overview of the period in analysis. For a micro analysis, there are the following four tabs. The technology ones are more dedicated to the production sector and the consumer ones to the consumption sector.

The day results by technology are represented in Figs. 12 and 13.

It is divided in economical items (variable costs, constant costs and total costs) and technological items (consumption, production mix, energy deficit and load diagram). The data are for a day in a year. The days are divided in the following typical days: Summer Week, Summer Weekend, Summer Week Holidays, Summer Weekend Holidays, Winter Week, Winter Weekend, Winter Week Holidays, Winter Weekend Holidays and Higher Energy Consumption. The data and the graphics change automatically when the user chooses the type of day to simulate.

Figure 14 represents the similar data for a selected year. Instead of a load diagram, there is a load duration diagram.

The consumer tab for a day is represented in Fig. 15.

For the three different sectors in study (households, industry and services), it is shown the total and unit cost, price and deficit. Also, there is the cost per GWh, per capita and per GDP, as well as the price sensitivity to the price of coal and to the price of gas. The consumer data (by year) tab has similar data for a selected year and is represented in Fig. 16.

\section{Results}

In the task of decision support, the optimal solution might be irrelevant. The major contribution to decision support is the model construction, the discussions necessary for this construction and the reflections on the results obtained. 


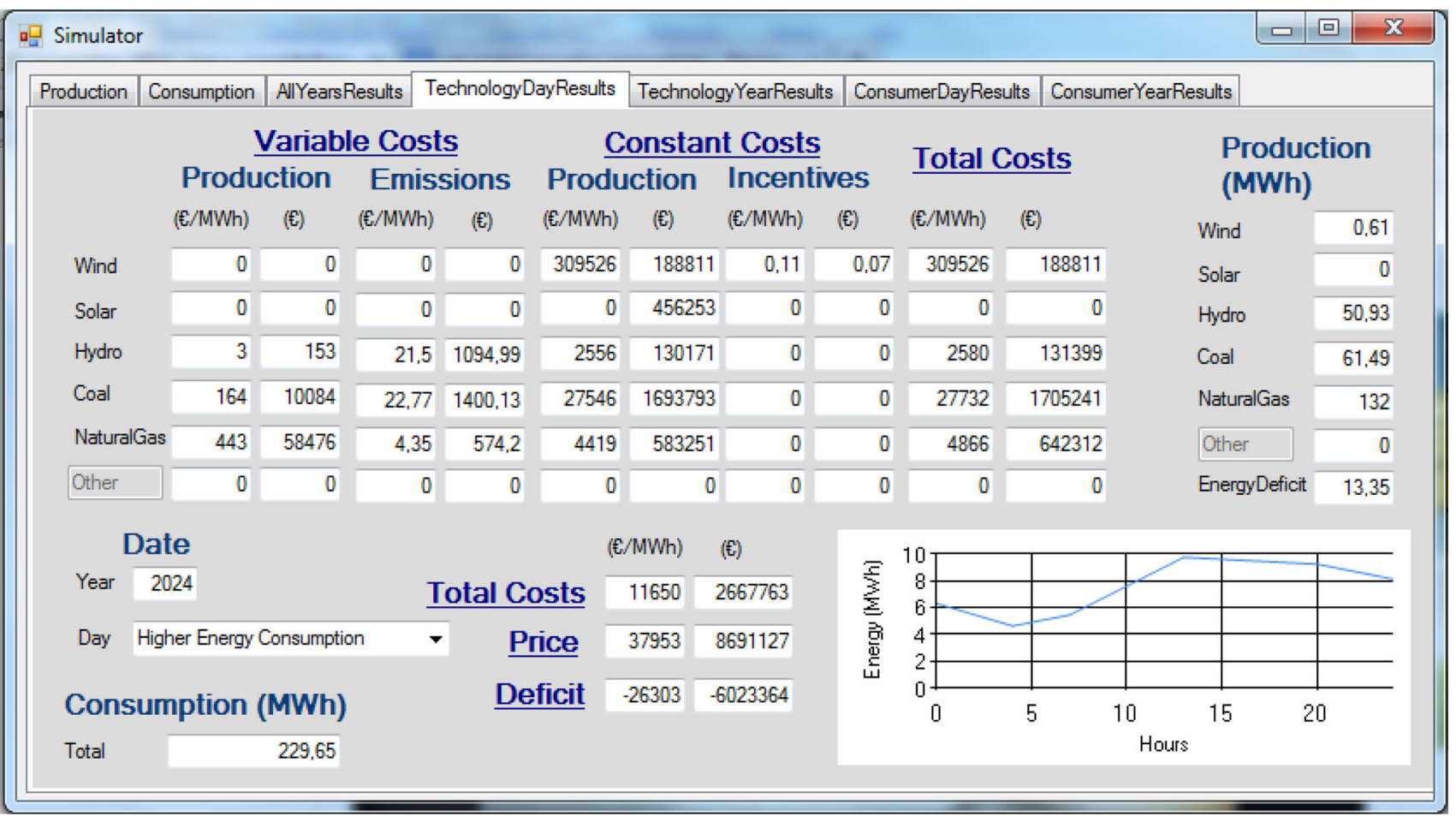

Fig. 12 Technology output (by day) tab: example 1

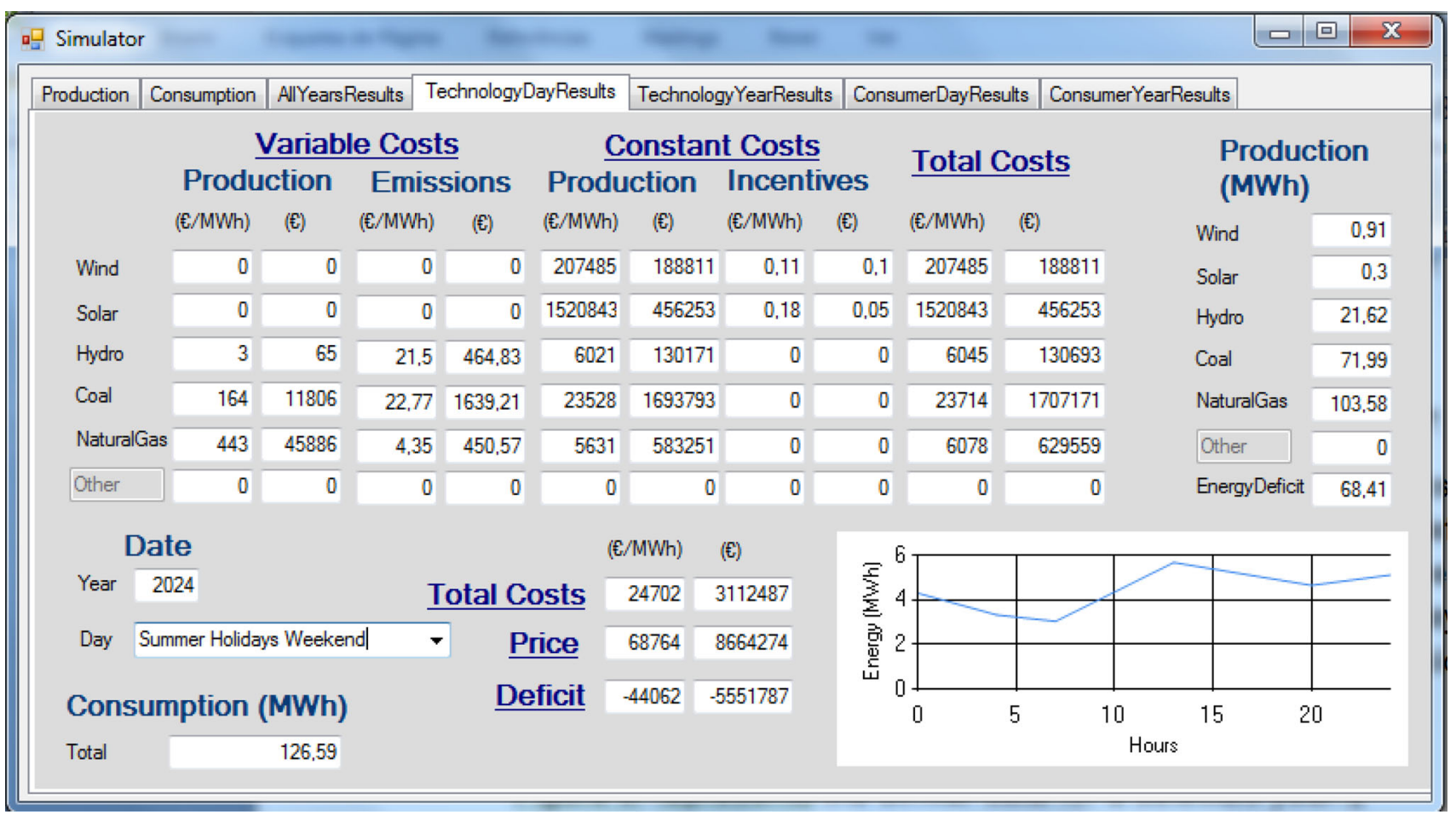

Fig. 13 Technology output (by day) tab: example 2

Based on the performance indicators chosen, the different users of the DSS can quantify the impact of their decisions on the electricity system.
The simulated scenarios are presented in Table 6.

In all scenarios, it is assumed a GDP growth of $1 \%$ a year, according to the low scenario of the last available 


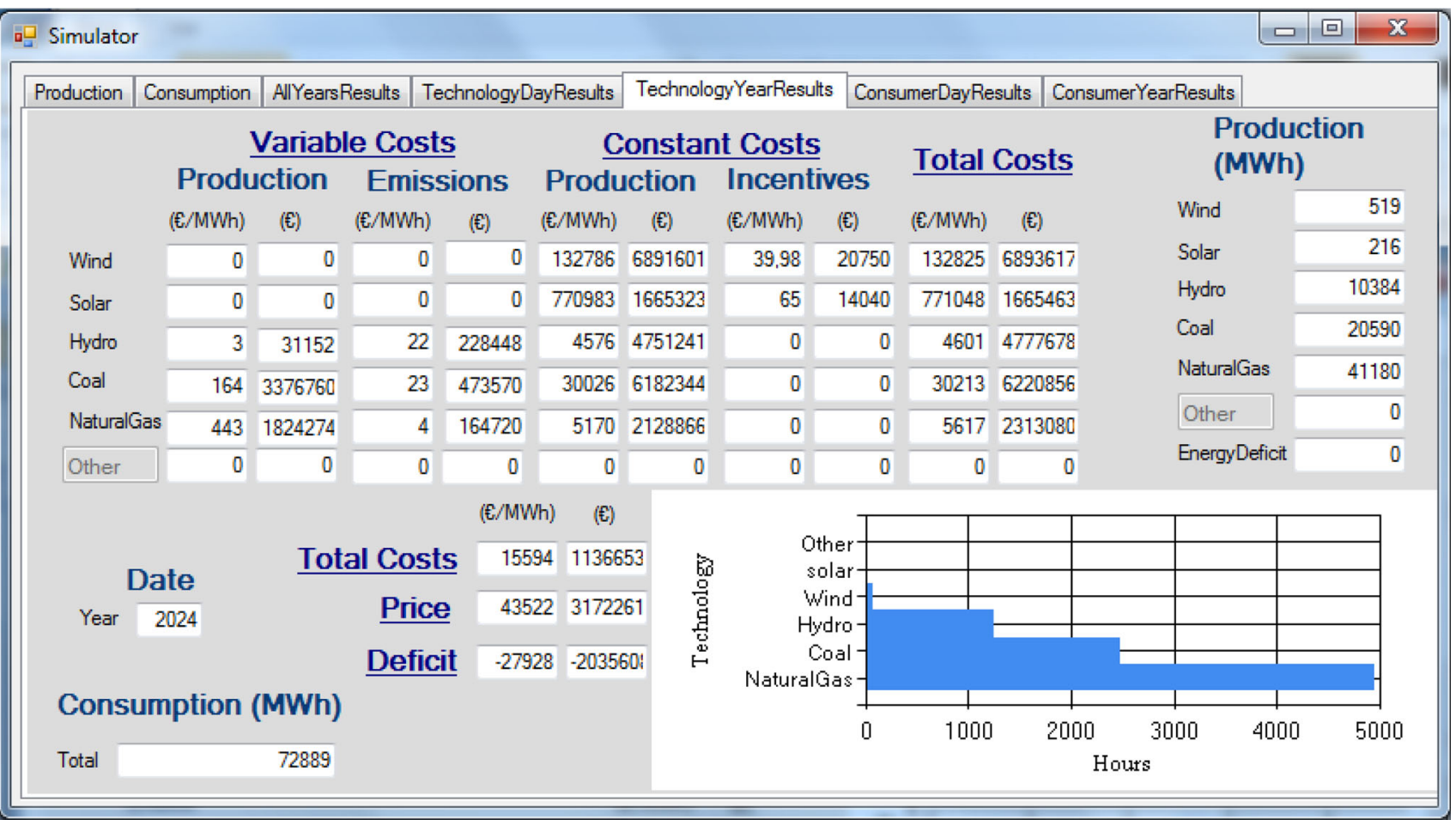

Fig. 14 Technology output (by year) tab

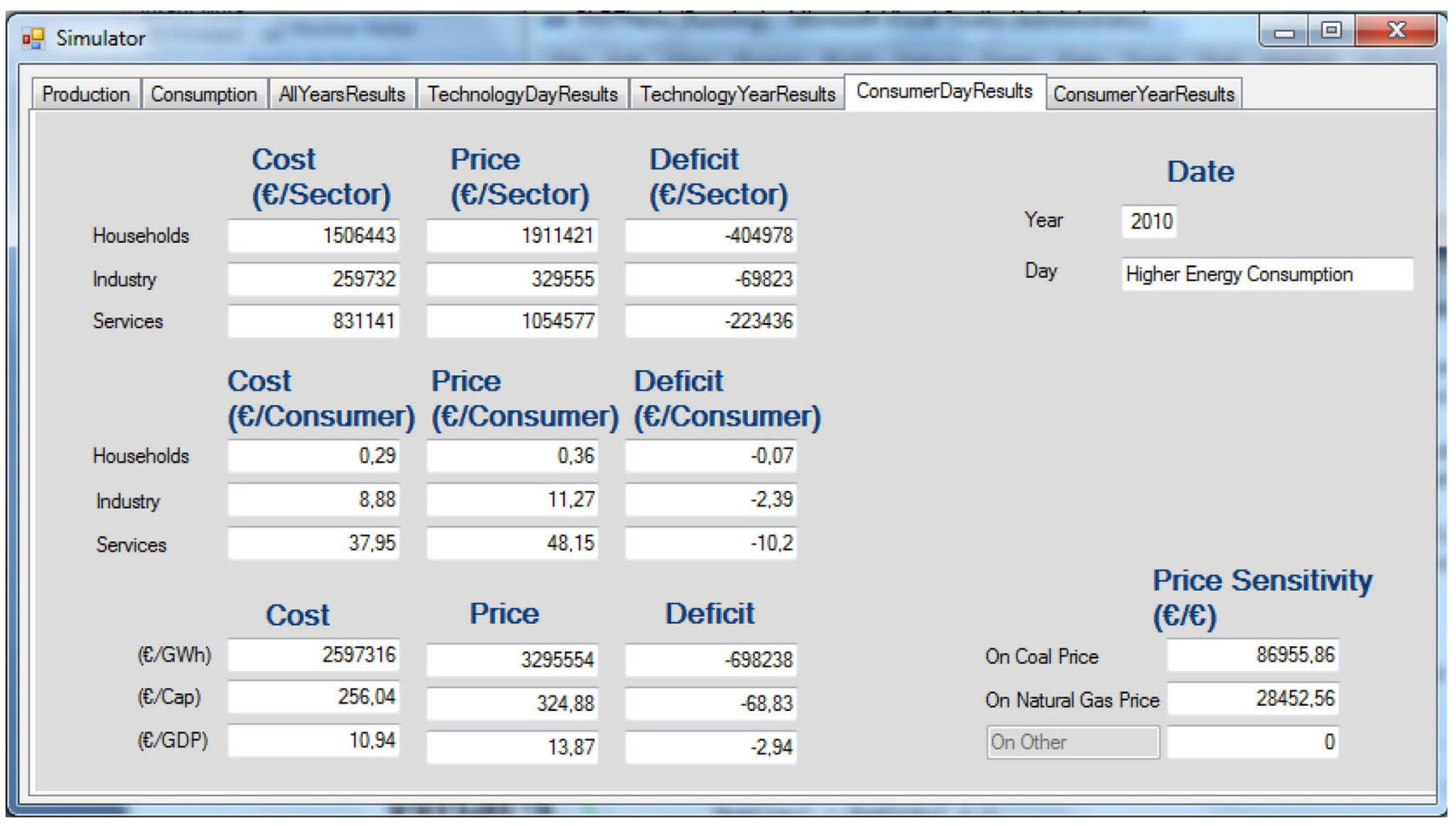

Fig. 15 Consumer data (by day) tab

Environmental Status Report (APA 2014). In all scenarios, it is assumed that energy prices increase $2 \%$ a year, following the increase in gas and electricity prices (Eurostat 2012a, b). It was used the base prices of 2013. It was assumed that the transmission and distribution losses are $7 \%$ of electricity demand and the self-production is $2 \%$ of 


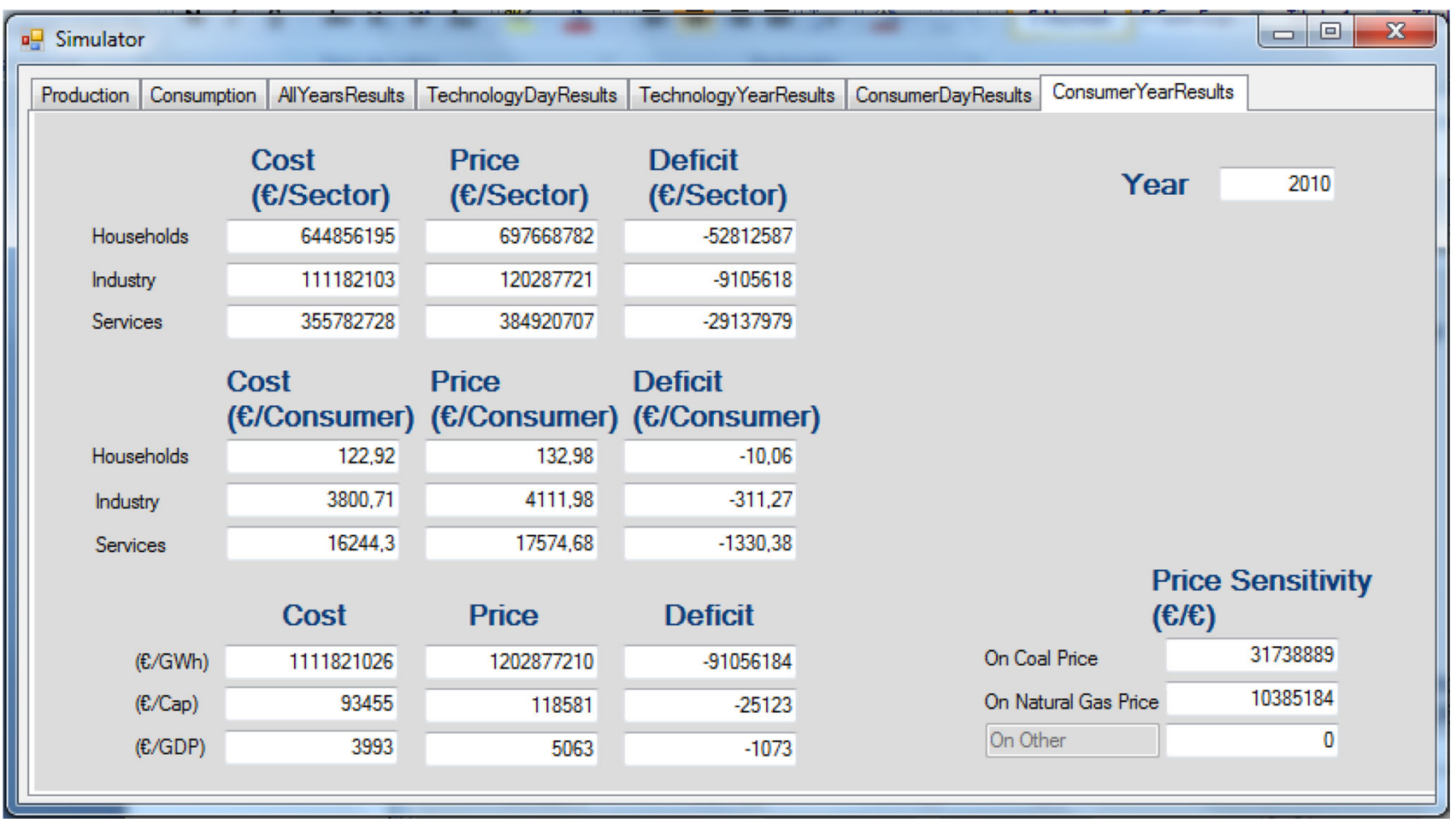

Fig. 16 Consumer data (by year) tab

electricity demand, according to the historic data of the Portuguese electricity sector (REN 2014). It was assumed that investment data for efficiency measures were obtained by weighted average of the potential savings. This simplification is a result of the availability of existing data, despite it is recognised that the ideal would be to have the potential of individual savings by technological groups. It was assumed that the solar thermal system is direct competitor of gas for water heating, and less important as an energy replacement electricity. So, it was not considered the potential energy savings from the solar thermal system. In Table 5, the benefits to investments in energy-efficiency measures are simplified by support to efficiency.

In the BAU scenario, it is assumed the continuity of the Government policy measures and the continuity of current behaviours in consumption. In this scenario, consumers do not make decisions on investments, being a scenario without technological change.

Table 6 Scenarios

\begin{tabular}{|c|c|c|}
\hline & Designação & Descrição \\
\hline \multirow[t]{2}{*}{ Baseline } & $B A U$ & $\begin{array}{l}\text { Scenario assuming the continuation of current policy measures and developments in consumption. It } \\
\text { is a scenario without technological change }\end{array}$ \\
\hline & No IncentiveEE & Scenario which assumes that there is no support to efficiency. It will be used as the baseline scenario \\
\hline \multirow[t]{3}{*}{$\begin{array}{l}\text { Support to } \\
\text { efficiency }\end{array}$} & $\begin{array}{l}\text { IncentiveEE } \\
\text { Minimum }\end{array}$ & Scenario with support to efficiency of $10 \%$ for households and of $15 \%$ for the industry \\
\hline & $\begin{array}{l}\text { IncentiveEE } \\
\text { Medium }\end{array}$ & Scenario with support to efficiency of $20 \%$ to households and of $25 \%$ for the industry \\
\hline & $\begin{array}{l}\text { IncentiveEE } \\
\text { Maximum }\end{array}$ & Scenario with support to efficiency of $25 \%$ to households and of $40 \%$ for the industry \\
\hline Tariff support & $\begin{array}{l}\text { MaskPrice No } \\
\text { IncentiveEE }\end{array}$ & $\begin{array}{l}\text { Scenario which assumes that there is no support to efficiency and that there is a } 40 \% \text { support rate for } \\
\text { the industry and for services }\end{array}$ \\
\hline \multirow[t]{2}{*}{$\begin{array}{l}\text { With solar self- } \\
\text { production }\end{array}$} & $\begin{array}{l}\text { Solar No } \\
\text { IncentiveEE }\end{array}$ & Scenario with the introduction of solar self-production and there is no support to efficiency \\
\hline & $\begin{array}{l}\text { Solar IncentiveEE } \\
\text { Medium }\end{array}$ & $\begin{array}{l}\text { Scenario with the introduction of solar self-production. Scenario with support to efficiency of } 20 \% \\
\text { for households and } 25 \% \text { for the industry }\end{array}$ \\
\hline
\end{tabular}


In all the other scenarios, it is assumed that consumers know their savings potential and know the investment required to implement them. These pair of values of potential savings and the investment required to implement it are aggregated for each payback period. Based on these values, consumers make the decision on the amount to invest to implement savings for each payback period.

In the scenario No IncentiveEE, it is assumed that domestic consumers and industry make the investment decision without Government benefits.

In support to efficiency scenarios, IncentiveEE, it is assumed that there is an available Government support for households and for the industry to implement energy-efficiency measures. The three scenarios to support efficiency (Minimum, Medium and Maximum) simulate different levels of Government benefits. In all scenarios, it is assumed that the fixed Government benefits are null and there are only variable Government benefits, according to the amount invested by each sector. The cost of Government benefits is distributed to the electricity sector, being added to the total cost of electricity. For households, the short-term investment return incentive is for the replacement of inefficient equipment fleet (measured R\&S4M1, R\&S4M2 and R\&S4M3 the PNAEE) and medium-term investment return incentive is for refurbishment (measures R\&S4M5, R\&S4M6 and R\&S4M7 the PNAEE). For industry, the short-term investment return incentive is for application of electronic variable speed drives and the medium-term investment return incentive is for the replacement of electrical machines (ADENE 2010b).

In the tariff support scenario, MaskPrice, it is assumed a subsidy of $40 \%$ of the electricity tariff price to industry. The tariff subsidisation scenarios quantify the behaviour of the national electricity sector with tariffs for industry similar to France, one of the Portuguese direct competitors. This scenario quantifies the effect of tariff subsidisation on consumer's decision making in energy-efficiency investments.

In the self-production scenarios, Solar, it is assumed that consumers make the decision to invest in self-production off the grid, with the sole purpose of satisfying own consumption, and without any support. It is presented the scenario Solar No IncentiveEE and scenario Solar IncentiveEE Medium. It verifies the consumeŕs decision making in energy-efficiency investments in the influence of solar self-production.

The performance indicators chosen are presented in Table 7. The indicators are divided into three areas.

The scenarios show that without decision on consumer side, the demand continuously grows, as shown in Fig. 17. The growth is almost linear, despite the fact that there is a smashing effect due to the price.
Figure 20 also shows that even without incentive from the Government to the implementation of energy-efficiency measures, consumers reduce their demand. In the scenarios with decision on self-production by solar power, the demand decreases but the consumption, illustrated in Fig. 18, is higher than in the respective scenario without self-production by solar power. This is because the investment on self-production reduces the demand, thereby reduces the tariff cost, so increases the payback time. Also, the electric energy intensity increases because it is related to the consumption.

When analysing by sector, it is possible to conclude that the behaviour of industry is concordant with the consumption in general, as it is illustrated in Fig. 22. The difference between the scenario No IncentiveEE and the scenario IncentiveEE minimum is not relevant, but between these two scenarios and the scenarios IncentiveEE with more support, Fig. 19 shows a relevant difference right on the beginning of the period. This happens because the industry in Portugal already implemented the low payback investments and needs support to implement the rest. Regarding the consumption in industry, illustrated in Fig. 20, it is possible to understand the impact of the solar investments in less energy-efficiency measures implementation.

The demand for households, illustrated in Fig. 24, is similar to the general demand but more significant right on the beginning of the period, proving that there is profitable investments to make on energy-efficiency savings. For the scenario MaskPrice No IncentiveEE, the behaviour of consumers is quite different. The industry demand increases due to the fact that industry has a tariff subsidy. This fact increases the costs of electricity that is reflected in the tariff for all consumers. Since households don't have a tariff subsidy, this smashing effect is more significant to them. Regarding the consumption in households, illustrated in Figs. 21 and 22, it is more noteworthy the impact of the solar investments in less energy-efficiency measures implementation.

The average price increases in the reference scenarios, due to the increasing costs to the system, as illustrated in Figs. 23 and 24. However, in the scenarios with Support for efficiency, the rate is lower. Especially for households, the average price decreases in the Solar scenarios, due to the reduction of demand, thus the costs to the system. For industry, the average price also increases in the MaskPrice scenario but with a higher rate, similar to the BAU scenario. For households, the average price in the MaskPrice scenario has a significant increase in the second year because these consumers do not have support for tariff, and the costs to the system increase due to the increase in industry electricity demand. 
Table 7 Performance indicators

\begin{tabular}{|c|c|c|c|}
\hline Domain & $\begin{array}{l}\text { Performance } \\
\text { indicator }\end{array}$ & Description & Worth \\
\hline \multirow[t]{2}{*}{ Energy } & $\begin{array}{l}\text { Total electricity } \\
\text { demand }\end{array}$ & $\begin{array}{l}\text { The amount of electricity required by consumers (or demand), } \\
\text { including energy losses in the network }\end{array}$ & $\begin{array}{l}\text { Evaluates the effectiveness of the simulated } \\
\text { Government measures in energy reduction }\end{array}$ \\
\hline & $\begin{array}{l}\text { Total electricity } \\
\text { consumption }\end{array}$ & $\begin{array}{l}\text { The sum of total demand of electricity to the grid with the } \\
\text { self-production }\end{array}$ & \\
\hline \multirow[t]{4}{*}{$\begin{array}{l}\text { Socio- } \\
\text { economic }\end{array}$} & Tariff cost & $\begin{array}{l}\text { The monetary amount spent by consumers to receive the } \\
\text { electricity }\end{array}$ & $\begin{array}{l}\text { Evaluates the economic contribution of } \\
\text { consumers, charged by the tariff }\end{array}$ \\
\hline & Cost to consumer & $\begin{array}{l}\text { The sum of the tariff cost with their own investments in } \\
\text { energy efficiency and self-production }\end{array}$ & $\begin{array}{l}\text { Evaluates the weight of electricity in family } \\
\text { budget and in industry costs }\end{array}$ \\
\hline & $\begin{array}{c}\text { Total cost of } \\
\text { electricity }\end{array}$ & $\begin{array}{l}\text { The monetary amount needed to deliver the electricity to } \\
\text { consumers }\end{array}$ & Evaluates the cost of the electric system \\
\hline & $\begin{array}{l}\text { Total cost to } \\
\text { citizen }\end{array}$ & $\begin{array}{l}\text { The maximum value between tariff cost and total cost of } \\
\text { electricity }\end{array}$ & $\begin{array}{l}\text { Evaluates the real cost of electricity and } \\
\text { reveals the hidden subsidies }\end{array}$ \\
\hline Environment & $\begin{array}{l}\text { Environmental } \\
\text { pressure }\end{array}$ & It includes all impacts of the energy life cycle & $\begin{array}{l}\text { Evaluates the environmental impact of the } \\
\text { electricity sector }\end{array}$ \\
\hline
\end{tabular}

Fig. 17 Electricity demand

Fig. 18 Electricity consumption
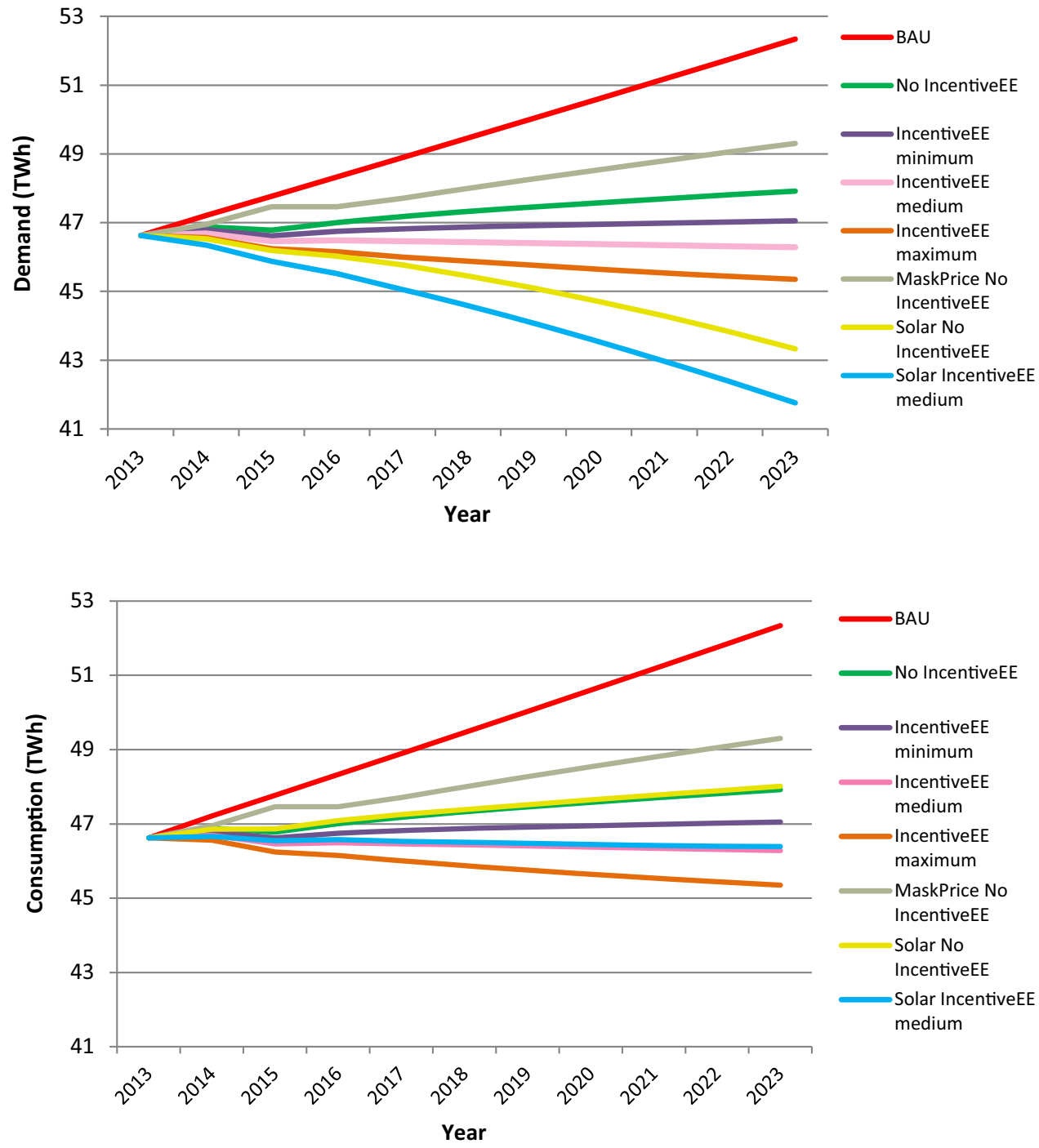
Fig. 19 Electricity demand by industry

Fig. 20 Electricity consumption by industry
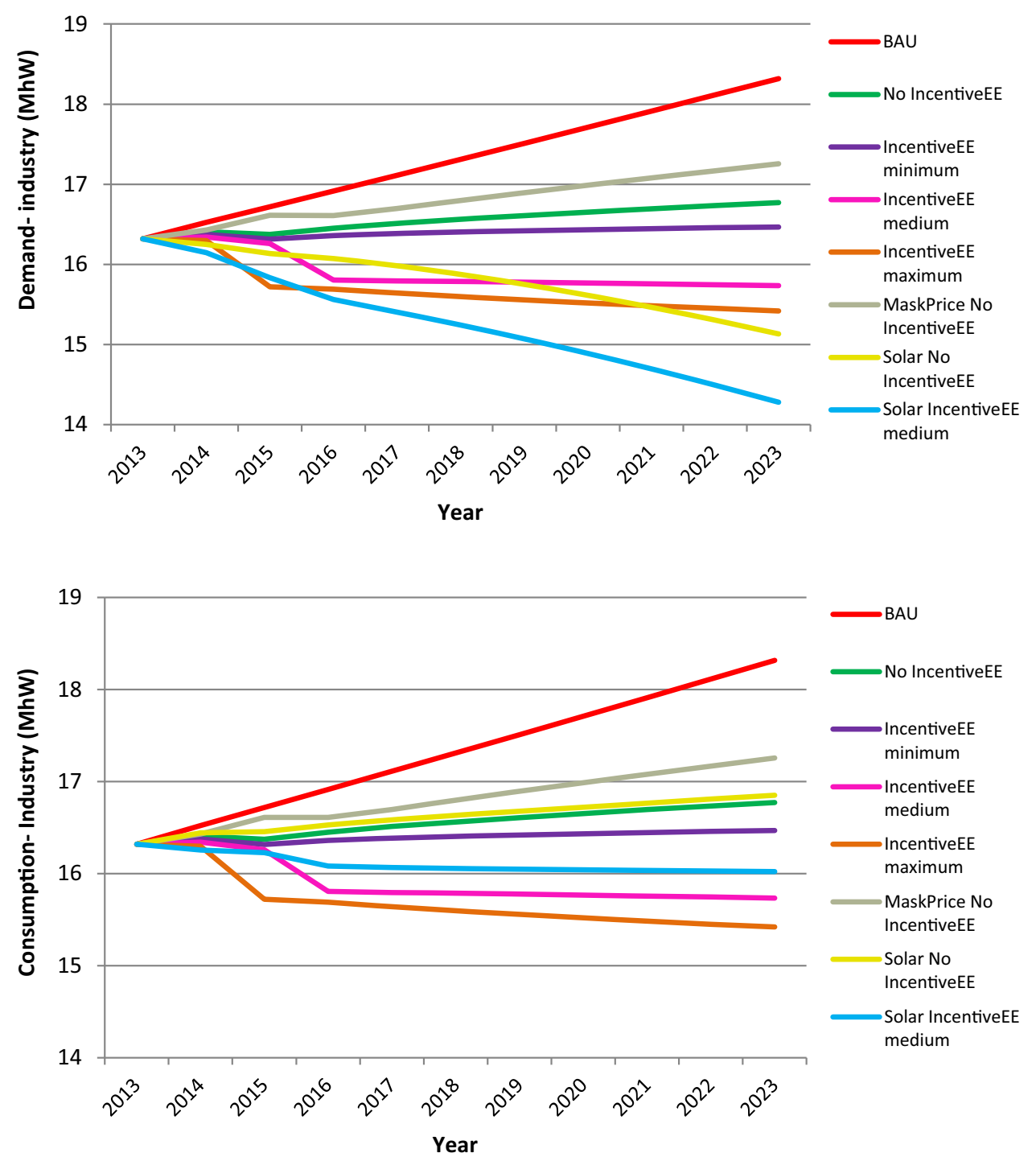

The decision making on energy-efficiency measures require investment but reduces the tariff. Observing Figs. 25, 26 and 27, it is possible to realise the economic advantage of the decisions by comparing the total costs of the different scenarios with the BAU scenario. It is also possible to see that the total costs of the investments on the Solar scenarios are lower than the total costs of the respective scenario without solar investment.

The total cost of electricity profile is similar to all consumers and to industry. However, for households, there are some important differences in the MaskPrice scenario.

The total cost of electricity for households in the MaskPrice scenario is bigger than the Total cost of electricity for the No IncentiveEE scenario at the beginning of the period, because it is an increase in the investments in energy-efficiency measures due to higher tariff price. In the third year, the total cost of electricity for households is similar in the BAU, the No IncentiveEE and the MaskPrice scenarios. After that year, the total cost of electricity for households is lower in the MaskPrice scenario.

Figure 28 shows the Total cost of electricity, i.e. the total cost of delivering electricity to consumers. It is possible to observe that the total cost of electricity is significantly high in the MaskPrice scenario and with a higher growth rate.

It is interesting to observe in Fig. 29 that the total cost of electricity is approximately constant in the IncentiveEE scenarios: the decision making by consumers prevents the increase in the total cost of electricity of the BAU scenario. In the Solar scenarios, the total cost of electricity decrease because it joins the demand decrease by investments in energy efficiency and in self-production.

Due to tariff support in the MaskPrice scenario, there is a cost that it is not paid by consumers. These cost work as a hidden subsidy that it will be paid for tax payers. Figure 30 shows that in a medium term, there is no economical advantage in tariff support. 
Fig. 21 Electricity demand by households

Fig. 22 Electricity consumption by households

Fig. 23 Electricity average price to industry
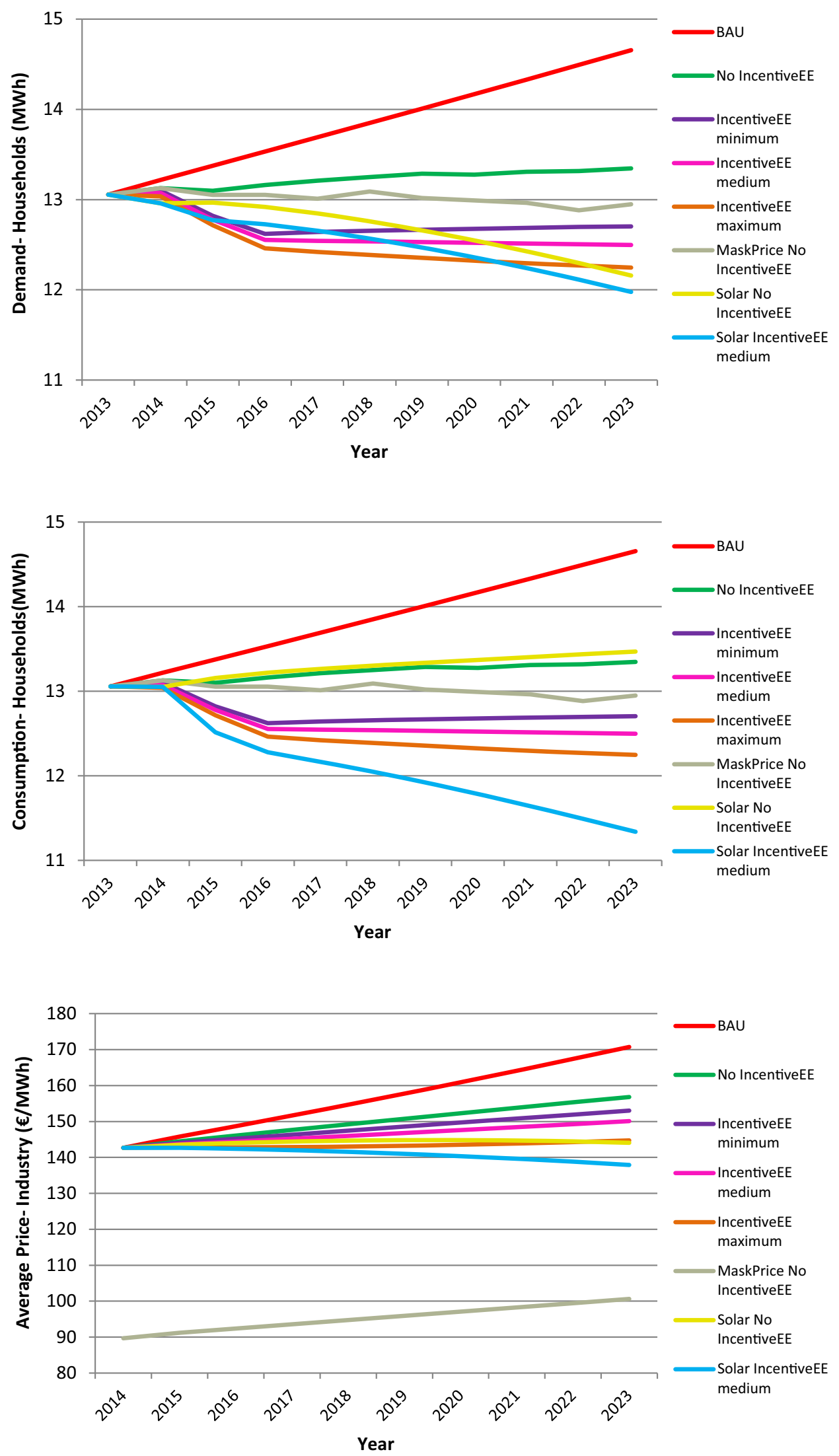
Fig. 24 Electricity average price to households

Fig. 25 Total cost of electricity to all consumer types

Fig. 26 Total cost of electricity to industry
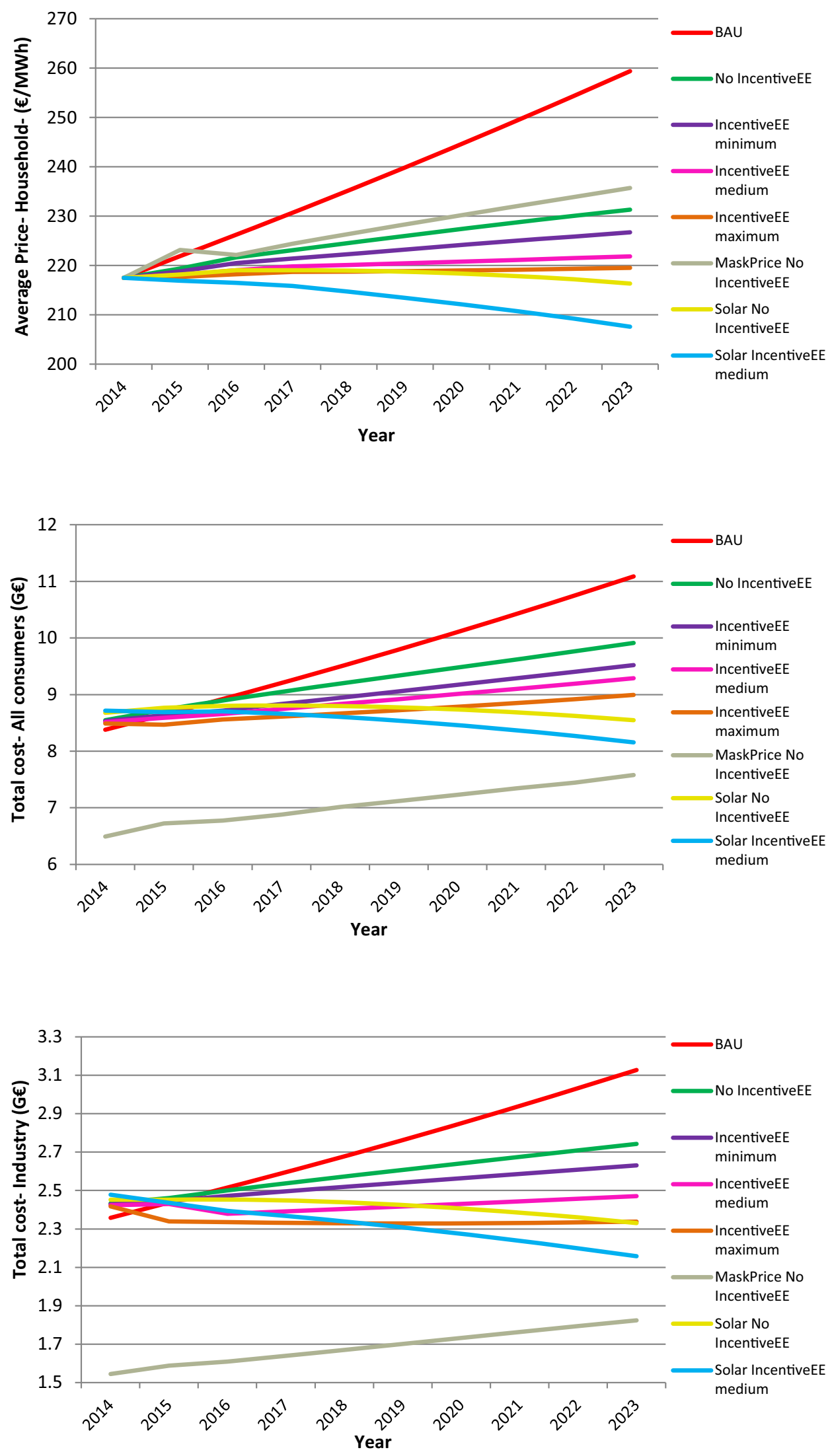
Fig. 27 Total cost of electricity to households

Fig. 28 Total cost of electricity to the system

Fig. 29 Total cost of electricity to the system without the MaskPrice scenario
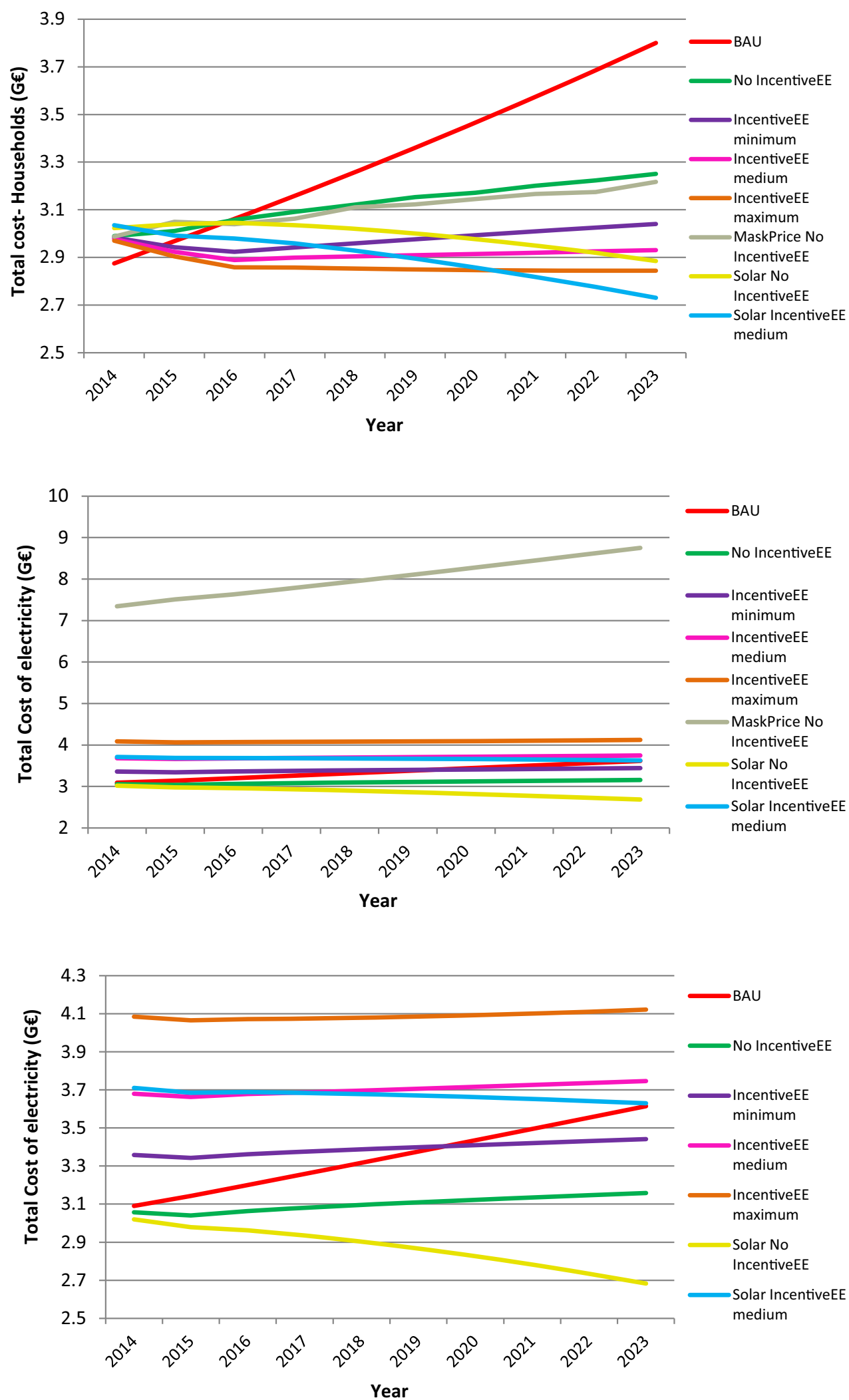

Figure 31 illustrates the Environmental pressure of electricity production. The Environmental pressure of electricity production is strictly linked with the demand. The higher the demand, the higher the increase in Environmental pressure of electricity production because there is an increase in the share of gas and coal in the energy mix. 
Fig. 30 Total cost of electricity to citizens
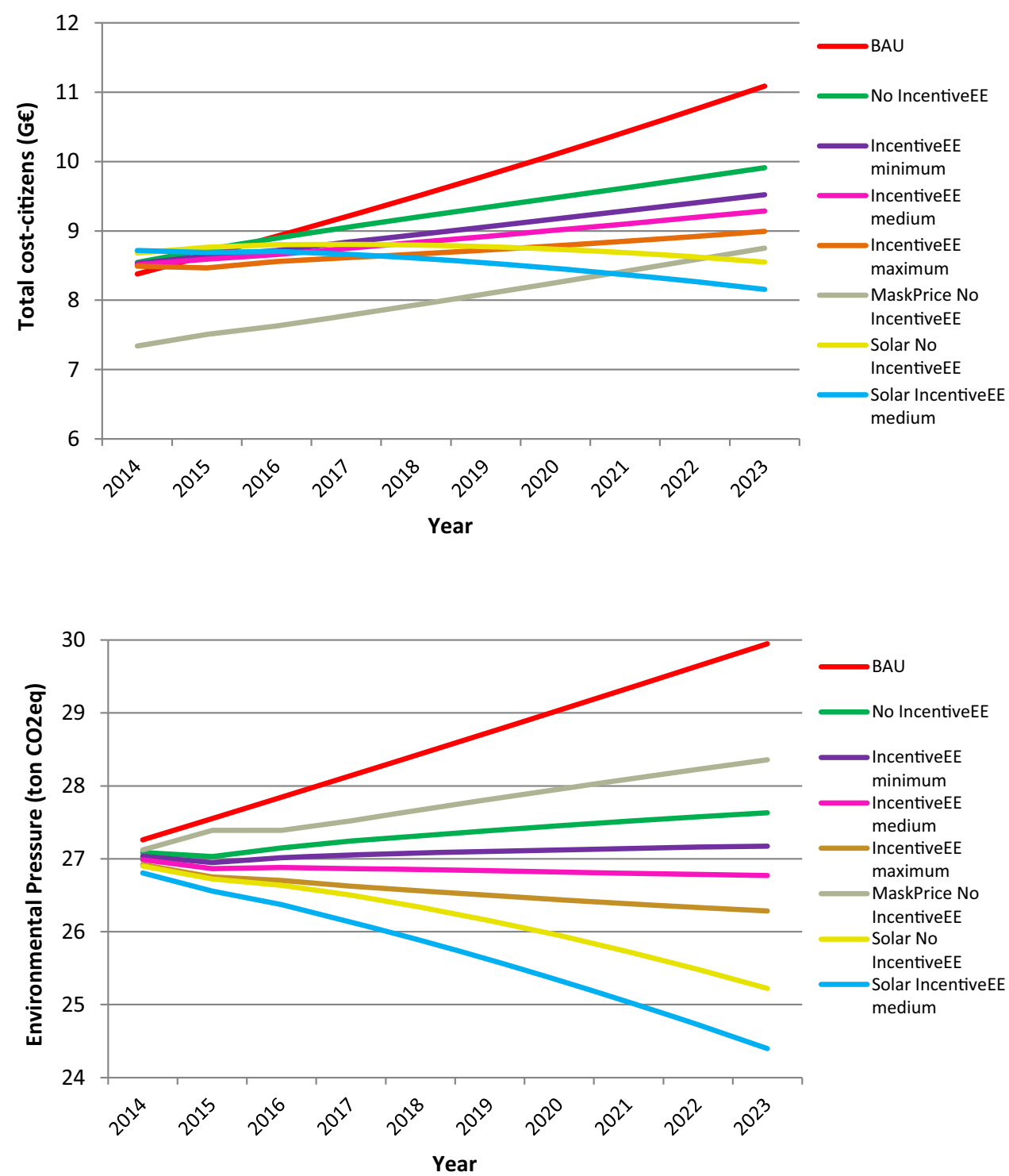

Fig. 31 Environmental pressure of electricity production
In the Solar scenarios, there is an increase in consumption. However, there is a decrease in Environmental pressure of electricity production because the demand is lower and the rest of energy is produced by Solar energy with lower Environmental pressure.

Figure 32 illustrates the relative performance indicators. It is possible to observe the magnitude of an indicator at the end of the period comparing to it in the beginning of the period.

\section{The role of the DSS within the national regulatory process}

The laws and the regulations of a particular Country are dynamic. This is due to some factors, namely the achievement of previous goals, the need to change instruments to achieve the goals, the mature of technologies available, the need for budget, the international agreements, and so on. The present DSS is very useful to test and experiment with no risk. For a particular Country, this DSS provides day ahead foreseen impacts and allows discarding instruments. It also identifies losers and major players, which gives opportunity to make plans to compensate them, avoid creation of poor players and prevents criticisms that damage public image.

\section{Conclusions}

The multifaceted electricity sector is a complex and dynamic system, with their characteristics and with agents influencing each other. The consumers' needs and decisions to invest establish the demand. The producers' decisions to 
Fig. 32 Evolution of performance indicators

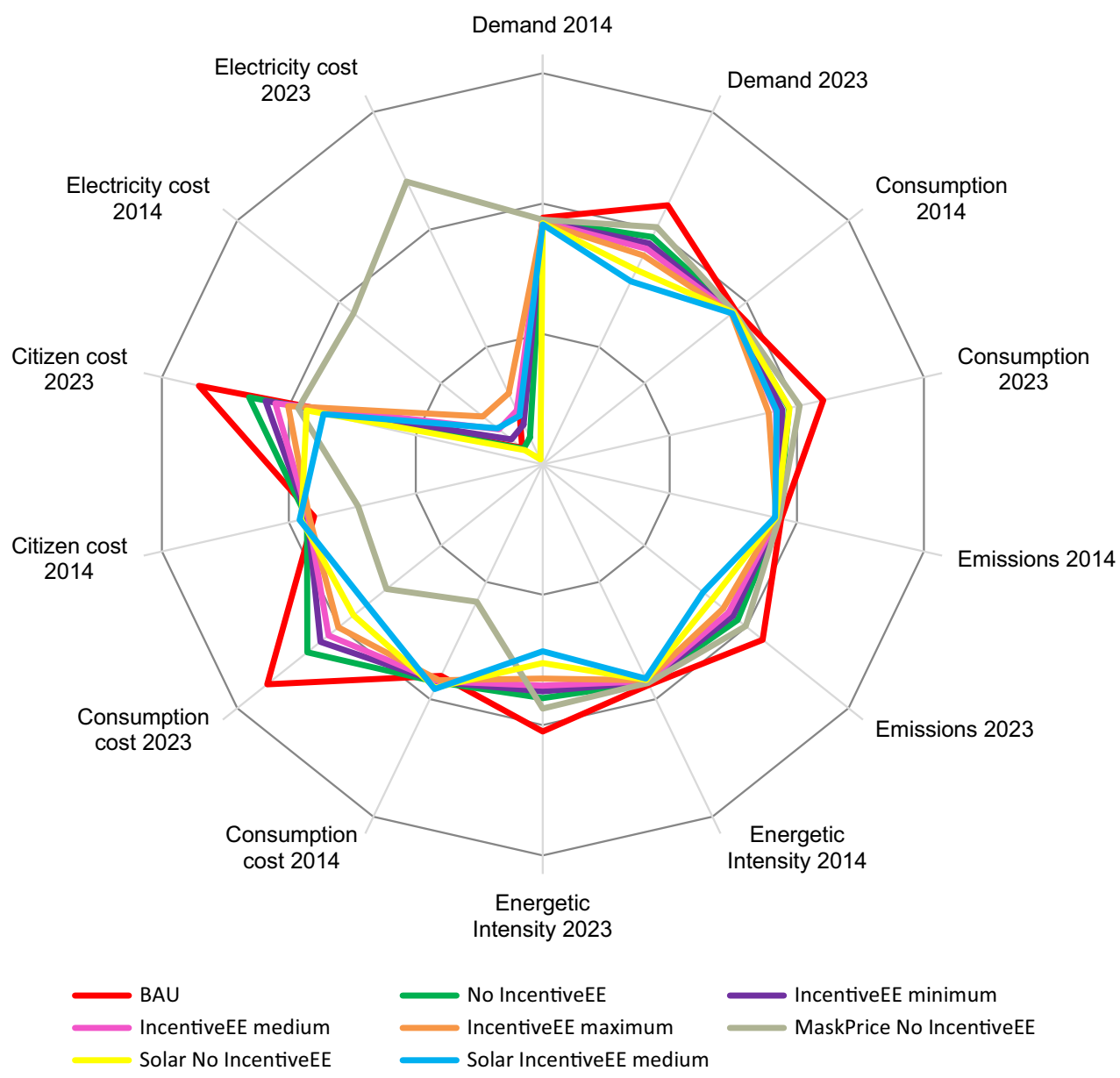

shut down or to invest in power plants establish the production capacity and the production costs. The Government decisions on incentives influence the decisions to invest.

The main contributions of the present paper is to provide a tool to analyse and test the Portuguese case without risk, to provide results that would allow to make quantitatively judgements and to eliminate unfeasible options.

The decision support system developed helps to understand the effect of these decisions. Thereby, the decision support system is a tool that has a wide range of interested users. Developing a user friendly tool helps an electricity sector agent to organise the data to be analysed before make any decision.

The present model allows the user to interact step by step in every simulation (i.e. every year). The model generates forecast data for the next period and waits for the user to confirm or correct it before running again. That way, the user can also play wildcards (in a positive or negative way), introduce structural changes, experiment emerging of a new technology paradigm and implement consumption behaviours change.

The conclusions presented here are related to the simulated scenarios in the assembled decision support tool and cannot be seen as dogmas or guidelines. From the several scenarios results, one can conclude that there is much uncertainty about the future, but business as usual, BAU, should not last for much longer.

It is possible to understand that incentives have a key role to guide the market agents on their decisions. The support to tariff leads to an increase in demand, costs and production while reduces the monetary contribution of the consumers. Moreover, the support to tariff increases the payback of investments in energy-efficiency measures, aggravating the increasing demand problem. The support for efficiency reduces the demand and, in medium term, reduces the total electricity cost. One should not forget that the increase in demand will force the investment in new power plants and in the grid capacity.

\section{References}

Abreu C (2007) Custos financeiros e sociais da geração de electricidade em parques eólicos. Universidade do Minho

Bosquet Benoit (2000) Environmental tax reform: does it work? A survey of the empirical evidence. Ecol Econ 34(1):19-32 
Barros T (2014) Previsão de carga-Comparação de técnicas. (Master), Faculdade de Engenharia da Universidade do Porto.

Blarke M (2015) COMPOSE: compare options for sustainable energy. http://homes.et.aau.dk/mbb/compose.htm

Boucinha J (1991) Electricty demand trends in Portugal. In: Paper presented at the ELAB-Encontro Luso Afro-Brasileiro de Redes de Energia

Branquinho P (2014) Modelos de Previsão do Consumo Energético no Sector Residencial. (Master), IST

Cabral A (2012) Tributação da electricidade num contexto ambiental. (Master), Universidade Católica Portuguesa do Porto

Capros P (1995) Integrated economy-energy-environment models. In: Paper presented at the international symposium on electricity, health and the environment: comparative assessment in support of decision making, IAEA, Vienna, Austria

Carmona N (2006) Modelação Econométrica da Procura de Electricidade em Portugal Continental: Uma Aplicação Empírica. ISEG

COM (2009) Factsheets by Country. http://ec.europa.eu/energy/ energypolicy/factsen.htm

COM (2010) Taxation trends in the European Union: European Commission

Connolly D, Lundb H, Mathiesenb BV, Leahya M (2010) A review of computer tools for analysing the integration of renewable energy into various energy systems. Appl Energy 87(4):1059-1082

Dorf RC (1997) The electrical engineering handbook. CRC Press, Boca Raton

ECN (2012) On the design of an EU climate and energy policy framework for 2030 - with special reference to renewable energy Policy Studies: Energy research Centre of the Netherlands

EDP (2014) Origens da Eletricidade. http://www.edpsu.pt/pt/origem daenergia/Pages/OrigensdaEnergia.aspx

EEA (2012) Environmental tax reform in Europe: opportunities for eco-innovation (09 Jan 2012 ed.): European Environmental Agency

EEA (2013) Achieving energy efficiency through behaviour change: what does it take?: European Environmental Agency

EEA (2014) Resource-efficient green economy and EU policies: European Environmental Agency

Endesa (2014) Como é produzida a electricidade que consome? http:// www.endesa.pt/PT/iframe.asp

ERSE, Entidade Reguladora do Sector Energético (2014) Relatório Mercado Liberalizado de Eletricidade - Maio 2014

Eurostat. (2012a) Electricity prices for household consumers

Eurostat. (2012b) Gas prices for household consumers

EuroStat (2014) Statistics by theme. http://epp.eurostat.ec.europa.eu/ portal/page/portal/statistics/themes

Fortes P (2014) Clearing the cloudy crystall balls: hybrid modelling for energy and climate change mitigation scenarios-a case study for Portugal (Doutoramento), FCT

GALP (2014) Eletricidade: origens e impacte ambiental. http://www. galpenergia.com/PT/ProdutosServicos/Produtos/Eletricidade/ Centro-de-informacao/A-nossa-Energia/Paginas/A-nossa-Ener gia.aspx

GEOTA (2013) Reforma Fiscal Ambiental: fiscalidade e incentivos no sector energético
GBE, Green Budget Europe (2009) Economic Instruments for Energy Efficiency and the Environment In Policy Research Report (Ed.)

Grubb M, Kohler J, Anderson D (2002) Induced technical change in energy and environmental modeling: analytic approaches and policy implications. Annu Rev Energy Environ 27:271-308. doi:10.1146/annurev.energy.27.122001.083408

Horne M, Jaccard M, Tiedemann K (2005) Improving behavioral realism in hybrid energyeconomy models using discrete choice studies of personal transportation decisions. Energy Econ 27(1):59-77. doi:10.1016/j.eneco.2004.11.003

Hourcade J-C, Jaccard M, Bataille C, Ghersi F (2006) Hybrid modeling: new answers to old challenges introduction to the Special Issue of The Energy Journal. Energy J Hybrid Model. doi:10.5547/ISSN0195-6574-EJ-VolSI2006-NoSI2-1

IPCC (2006) Guidelines for National Greenhouse Gas. Energy Policy, 2

IPCC (2014a) Climate change 2014: impacts, adaptation, and vulnerability

IPCC (2014b) Climate change 2014: mitigation of climate change (Working Group III Technical Support Unit Ed.) Cambridge Publisher

Jaccard M, Nyboer J, Bataille C, Sadownik B (2003) Modeling the cost of climate policy: distinguishing between alternative cost definitions and long-run cost dynamics. Energy J 24(1):49-73

Jaccard M, Murphy R, Rivers N (2004) Energy-environment policy modeling of endogenous technological change with personal vehicles: combining top-down and bottom-up methods. Ecol Econ 51(1-2):31-46. doi:10.1016/j.ecolecon.2004.06.002

Metz B (2001) Climate change 2001: mitigation: contribution of Working Group III to the third assessment report of the Intergovernmental Panel on Climate Change (vol 3). Cambridge University Press

OECD (2015a) Aligning policies for a low-carbon economy. OECD Publishing

OECD (2015b) Policy challenges for the next 50 years. OECD Publishing

Pina A (2012) Supply and demand dynamics in energy systems modeling (PhD), IST

Pordata (2014) Base de dados de Portugal Contemporâneo. www. pordata.pt

REN, Redes Energéticas Nacionais (2014). www.ren.pt

Rivers N, Jaccard M (2005) Combining top-down and bottom-up approaches to energy-economy modeling using discrete choice methods. Energy J 26:183-106

Rivers Nic, Jaccard Mark (2006) Useful models for simulating policies to induce technological change. Energy Policy 34(15):2038-2047. doi:10.1016/j.enpol.2005.02.003

Rutherford TF, Böhringer C (2006) Combining top-down and bottomup in energy policy analysis: a decomposition approach, Discussion Paper No. 06-007, ftp://ftp.zew.de/pub/zewdocs/dp/ dp06007.pdf

Silva P (2014) Clearing the cloudy crystal balls: hybrid modelling for energy and climate change mitigation scenarios - a case study for Portugal $(\mathrm{PhD})$, FCT-UNL

Silva S, Soares I, Afonso Ó (2010) E3 Models Revisited. Universidade do Porto, Faculdade de Economia do Porto

Sutherland RJ (1991) Market barriers to energy-efficiency investments. Energy J 15-34 